San Jose State University

SJSU ScholarWorks

Master's Theses

Master's Theses and Graduate Research

1991

\title{
Arginine an essential residue that may be involved in the catalysis of chorismate mutase from Sorghum bicolor
}

Wilma H. Miller

San Jose State University

Follow this and additional works at: https://scholarworks.sjsu.edu/etd_theses

\section{Recommended Citation}

Miller, Wilma H., "Arginine an essential residue that may be involved in the catalysis of chorismate mutase from Sorghum bicolor" (1991). Master's Theses. 253.

DOI: https://doi.org/10.31979/etd.7n53-gvu9

https://scholarworks.sjsu.edu/etd_theses/253

This Thesis is brought to you for free and open access by the Master's Theses and Graduate Research at SJSU ScholarWorks. It has been accepted for inclusion in Master's Theses by an authorized administrator of SJSU ScholarWorks. For more information, please contact scholarworks@sjsu.edu. 


\section{INFORMATION TO USERS}

This manuscript has been reproduced from the microfilm master. UMI films the text directly from the original or copy submitted. Thus, some thesis and dissertation copies are in typewriter face, while others may be from any type of computer printer.

The quality of this reproduction is dependent upon the quality of the copy submitted. Broken or indistinct print, colored or poor quality illustrations and photographs, print bleedthrough, substandard margins, and improper alignment can adversely affect reproduction.

In the unlikely event that the author did not send UMI a complete manuscript and there are missing pages, these will be noted. Also, if unauthorized copyright material had to be removed, a note will indicate the deletion.

Oversize materials (e.g., maps, drawings, charts) are reproduced by sectioning the original, beginning at the upper left-hand corner and continuing from left to right in equal sections with small overlaps. Each original is also photographed in one exposure and is included in reduced form at the back of the book.

Photographs included in the original manuscript have been reproduced xerographically in this copy. Higher quality $6^{\prime \prime} \times 9^{\prime \prime}$ black and white photographic prints are available for any photographs or illustrations appearing in this copy for an additional charge. Contact UMI directly to order.

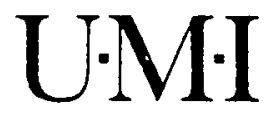

- University Microfilms International

A Bell \& Howell Information Company

300 North Zeeb Road. Ann Arbor, MI 48106-1346 USA

$313 / 761-4700 \quad 800 / 521-0600$ 


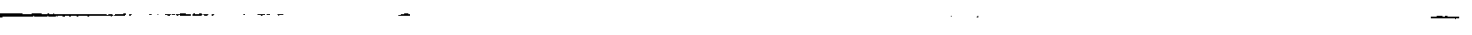


Arginine an essential residue that may be involved in the catalysis of chorismate mutase from Sorghum bicolor

\author{
Miller, Wilma Himaya, M.S.
}

San Jose State University, 1991

Copyright (C1992 by Miller, Wilma Himaya. All rights reserved.

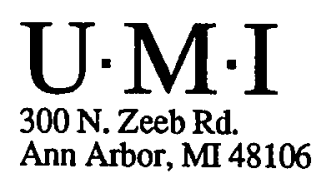




\title{
ARGININE AN ESSENTIAI RESIDUE THAT MAY BE INVOLVED IN THE CATALYSIS OF CHORISMATE MUTASE FROM SOrghum bicolor
}

\author{
A Thesis \\ Presented to \\ The Faculty of the Department of Chemistry \\ San Jose State University
}

\author{
In Partial Fulfillment \\ of the Requirements for the Degree \\ Master of Science
}

By

Wilma H. Miller

December, 1991 
Approved for the Department of Chemistry:

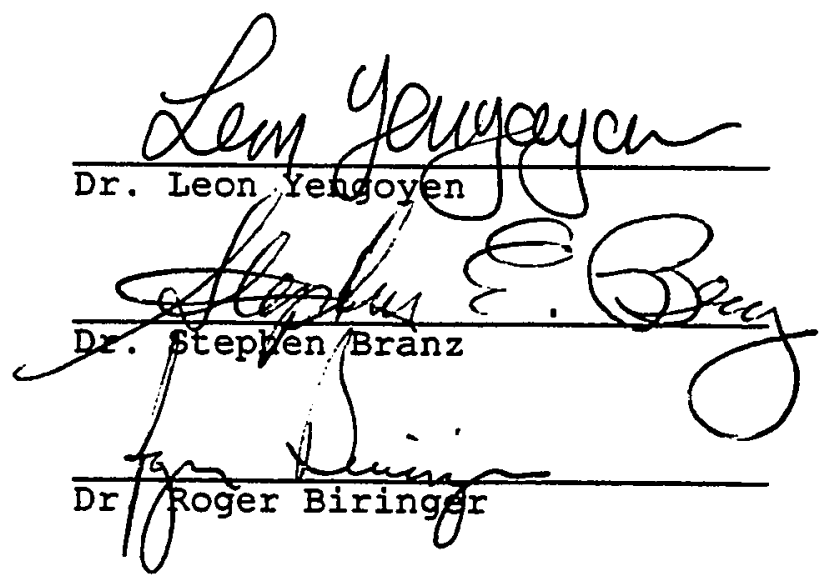

Approved for the University

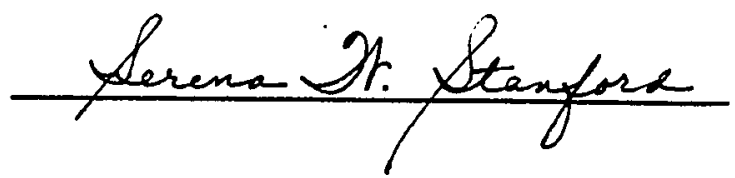


ABSTRACT

ARGININE AN ESSENTIAL RESIDUE THAT MAY BE INVOLVED IN THE CATALYSIS OF CHORISMATE MUSTASE FROM SOIghum bicolor.

by Wilma H. Miller

Chorismate mutase (EC 5.4.99.5) catalyzes the conversion of chorismate to prephenate in the first committed step which separates the synthesis of phenylalanine and tyrosine from the synthesis of tryptophan. Two isoforms of chorismate mutase have been observed in most higher plants, an unregulated form $(C M-2)$ and a regulated form (CM-1). CM-1 from Sorghum bicolor has been purified to homogeneity using tryptophan affinity chromatography. Substrate saturation kinetics and amino acid analysis of $\mathrm{CM}-1$ will be discussed. Modification experiments using p-hydroxyphenylglyoxal, a highly specific reagent for the guanidyl group of arginine, indicate that arginine may be involved in the catalysis of $\mathrm{CM}-1$. 
Dedicated to my Parents

William and Magdalena Miller 
ACKNOWLEDGEMENTS

Many thanks must be given to the many educators who have given me informative knowlege of what the sciences were about but more intuitively, what we don't and could know. Perhaps the most influencial educators of my life are my parents, William G. Miller and Magdalena H. Miller. They have bestowed upon their children the parental guide that made us responsible adults and the oppurtunity to explore and appreciate the individuals that we are today without conforming us to any ideals of what we should become.

Thanks to Sandoz Crop Protection for allowing me to do my thesis project at their company, and many thanks to the many employees there who were often happy to accomodate me into finishing my project. Thanks to Wayne Skinner for his expertise in elucidating the $\mathrm{N}$-terminal sequence of my enzyme and especially to Ian clousdale, who has given me the main emphasis of my thesis.

My most memorable days as a graduate student were often days of frustration, days when you repeatedly do a

experiment to get it to work but never do. It was days like these that you appreciate those who work closely with you to let you know that there are alternate ways. Two people come to my mind, Dr. Phil Haworth and Dr. Dan Siehl; to both of whom I owe my deepest gratitude.

Finally, I would like to thank Professor Dale Greenwalt, Professor Stephen Branz, Professor Leon Yengoyan and Professor Rodger Beringer for their suggestions and patience in proofreading my thesis.

Thank You Everyone

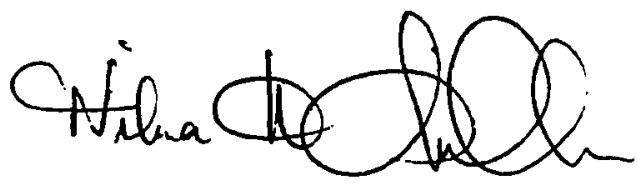




\section{TABIE OF CONTENTS}

Page

LIST OF ABBREVIATIONS

ix

LIST OF FIGURES

$\mathbf{x}$

LIST OF SCHEMES

$x i$

LIST OF TABLES

I. Introduction

A. The Shikimate Pathway in Plants 1

B. Plant Mutases 2

C. Bacterial Chorismate Mutases . 8

D. Chorismate-Prepenate Reaction 9

E. Proposed Reseach 12

$\begin{array}{ll}\text { II. Materials } & 16\end{array}$

$\begin{array}{ll}\text { III. Methods } & 17\end{array}$

A. Assay 17

B. Enzyme Purification 18

1. Plant Material 18

2. Extraction 19

3. Sephadex G-25 Desalting 19

4. DEAE-Cellulose Chromatography 20

vi 
5. Tryptophan Affinity Chromatography 21

6. SDS Electrophoresis 22

C. Protein Assay 23

1. Protein Dye 23

2. Absolute Protein Determination at

D. Preparation of CM-1 for Amino Acid
Analysis and N-terminal Sequencing

E. Tryptophan Analogs 26

F. CM-1 Modification $\quad 28$

1. Comparative Analysis of Lysine
and Arginine

2. Inactivation of $\mathrm{CM}-1$ with HPGO 29

3. Quantitation of the Number of Modified
Arginine Residues

VI. Results 34

A. CM-1 Purification 34

B. Saturation Kinetics 40

C. Tryptophan Analysis 43

D. Preparation of CM-1 for Amino Acid Analysis 48

E. Protein Determination at $280 \mathrm{~nm}$ and $235 \mathrm{~nm} 53$

F. Comparative Analysis of Lysine and Arginine Modification 53

G. CM-1 Inactivation by HPGO 60

H. Quantitation of Arginine-HPGO Derivative 63 
v. Discussion

A. CM-1 Purification and Characterization

70

B. Modification Experiments

VI. Iiterature Cited

viii 
LIST OF ABBREVIATIONS

$\begin{array}{ll}\text { ACN } & \text { Acetonitrile } \\ \text { BSA } & \text { Bovine Serum Albumin } \\ \text { EDTA } & \text { Ethylenediaminetetraacetic Acid } \\ \text { HPGO } & \text { p-Hydroxyphenylglyoxal } \\ \text { HPLC } & \text { High Performance Liquid Chromatography } \\ \text { KCl } & \text { Potassium Chloride } \\ \text { PAGE } & \text { Polyacrylamide Gel Electrophoresis } \\ \text { RP } & \text { Reverse Phase } \\ \text { SDS } & \text { Sodium Dodecylsulfate } \\ \text { V/V } & \text { Volume to Volume Ratio } \\ \text { W/V } & \text { Weight to Volume Ratio }\end{array}$


Figure 1. Chorismate-prephenate reaction 4

Figure 2. Aromatic amino acid biosynthesis 5

Figure 3. Proposed mechanism for the isomerization of chorismate to prephenate

Figure 4. Coupling reaction between Actigel A matrix and tryptophan

Figure 5. Actigel-Tryptophan Affinity column elution profile

Figure 6. SDS-PAGE of Tryptophan-Actigel Elution 39

Figure 7. SDS-PAGE molecular standard curve 41

Figure 8. Activation of CM-1 by Tryptophan 42

Figure 9. Reciprocal plot of $\mathrm{CM}-1$ Saturation by chorismate at 5 uM tryptophan

Figure 10. Hill plot of substrate saturation by chorismate at $1 \mathrm{UM}$ and 5 uM tryptophan 45

Figure 11. Analysis of CM-1 from actigel-tryptophan affinity column by $\mathrm{C}-4$ HPLC

Figure 12. Modification reaction with maleic anhydride

Figure 13. Arginine p-Hydroxyphenylglyoxal reaction 57

Figure 14. Modification with $6.4 \mathrm{mM}$ HPGO 61

Figure 15. Modification of Homogenous $\mathrm{CM}^{-1}$ with $0.2 \mathrm{mM} \mathrm{HPGO}$

Figure 16. BSA standard curves for extrapolating protein concentration and quantitating number of modified arginine groups

Figure 17. HPLC chromatograms of CM-1 from Sephadex G-25 (super fine 25-50u) 
Scheme 1. The shikimate pathway 3

Scheme 2. Proposed active site of CM-1 15

Scheme 3. Arginine Modification Scheme 65 
Table 1. HPLC parameters for preparation of enzyme for N-terminal sequence 27

Table 2. Purification scheme for $\mathrm{CM}-1 \quad 35$

Table 3. Percent $\mathrm{CM}-1$ activity using selected trytophan analogues

Table 4. N-terminal amino acid sequence for $\mathrm{CM}-1$

Table 5. Amino acid composition for $\mathrm{CM}-1$

Table 6. $\mathrm{mg} / \mathrm{ml}$ BSA calculated from absorbance difference at 235 and $280 \mathrm{~nm} \quad 54$

Table 7. Lysine and arginine modification of CM-1 59

Table 8. Possible number of arginine at active site of $\mathrm{CM}-1$ 
I. Introduction

The shikimate pathway is a vital process in nature since it imparts to plants and microorganisms the production of a wide array of compounds including the three aromatic amino acids, L-tyrosine, I-phenylalanine and I-tryptophan, and several vitamins, plant hormones, lignin precursors and phenolic (Jenson, 1985). The importance of this pathway stems from the fact that these compounds are essential precursors for protein synthesis as well as for secondary metabolism. Furthermore, since the pathway is non-mammalian, the production of the amino acids by plants is essential for survival not only of plants and microorganisms but of humans as well.

A. The Shikimate Pathway in Plants

The basic biochemical pathway for biosynthesis of the aromatic amino acids is present in all plants. Secondary metabolism in higher plants, however, is highly variable from one species to another. Individual plant species may produce a bewildering array of exotic and complex secondary metabolites indigenous only to its kind. For example, sorghum is well know for its production of cyanogenic glycosides, but most plants produce little or none of these compounds (Putnam, 1983). Regardless of the diversity of 
secondary metabolism in higher plants, up to $60 \%$ or more of the ultimate plant mass may consist of molecules that traversed the shikimate pathway (Jensen, 1985). Scheme I shows a composite of secondary metabolism derived from the metabolic capabilities of highly individualistic plant species.

The importance of this pathway has made it a very attractive process to study not only for fundamental plant biochemistry but also for herbicide discovery (Bartlett, et al, 1987). Glyphosate, a widely used herbicide acting within the pathway, exemplifies the potential for shikimate pathway inhibitors for efficacy and extremely low mammalian toxicity. One step in the shikimate pathway that is particularly interesting is the enzymatic conversion of chorismate to prephenate. This reaction is important because chorismate is a branch point intermediate serving the synthesis of L-tyrosine and L-phenylalanine by one branch and L-tryptophan by the other. The enzyme chorismate mutase (EC 5.4.99.5) catalyzes the conversion of chorismate to prephenate, leading to phenylalanine and tyrosine (see figure 1 and 2 ).

B. Plant Mutases

Plants exhibit one to three forms of chorismate mutase, 


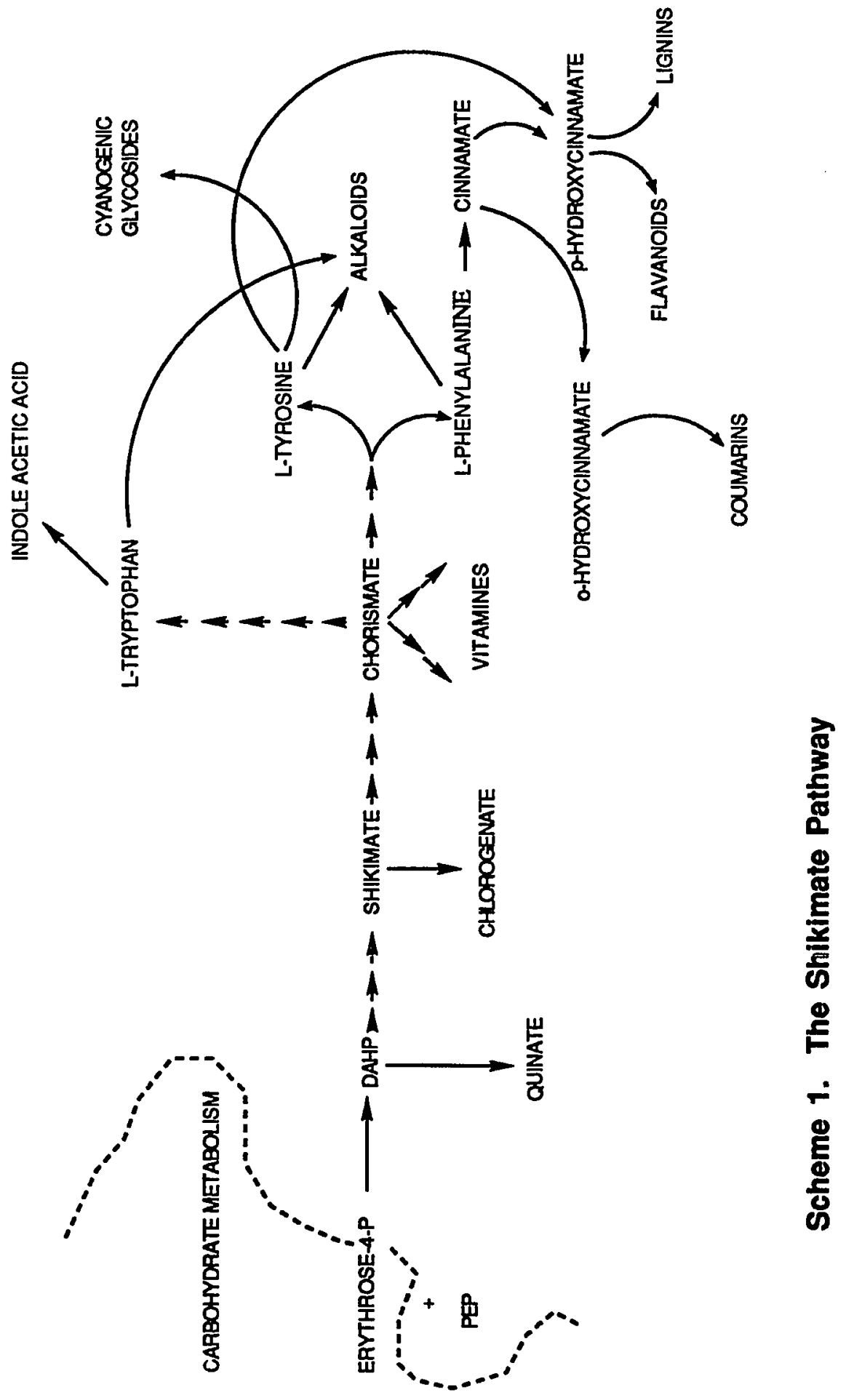


完

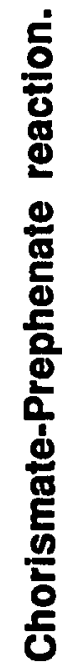

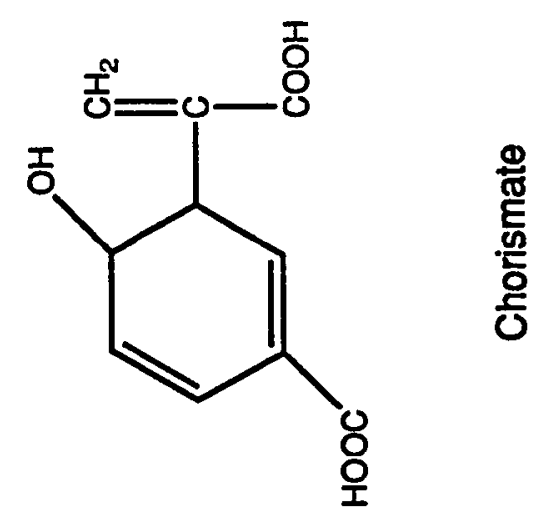

홍 


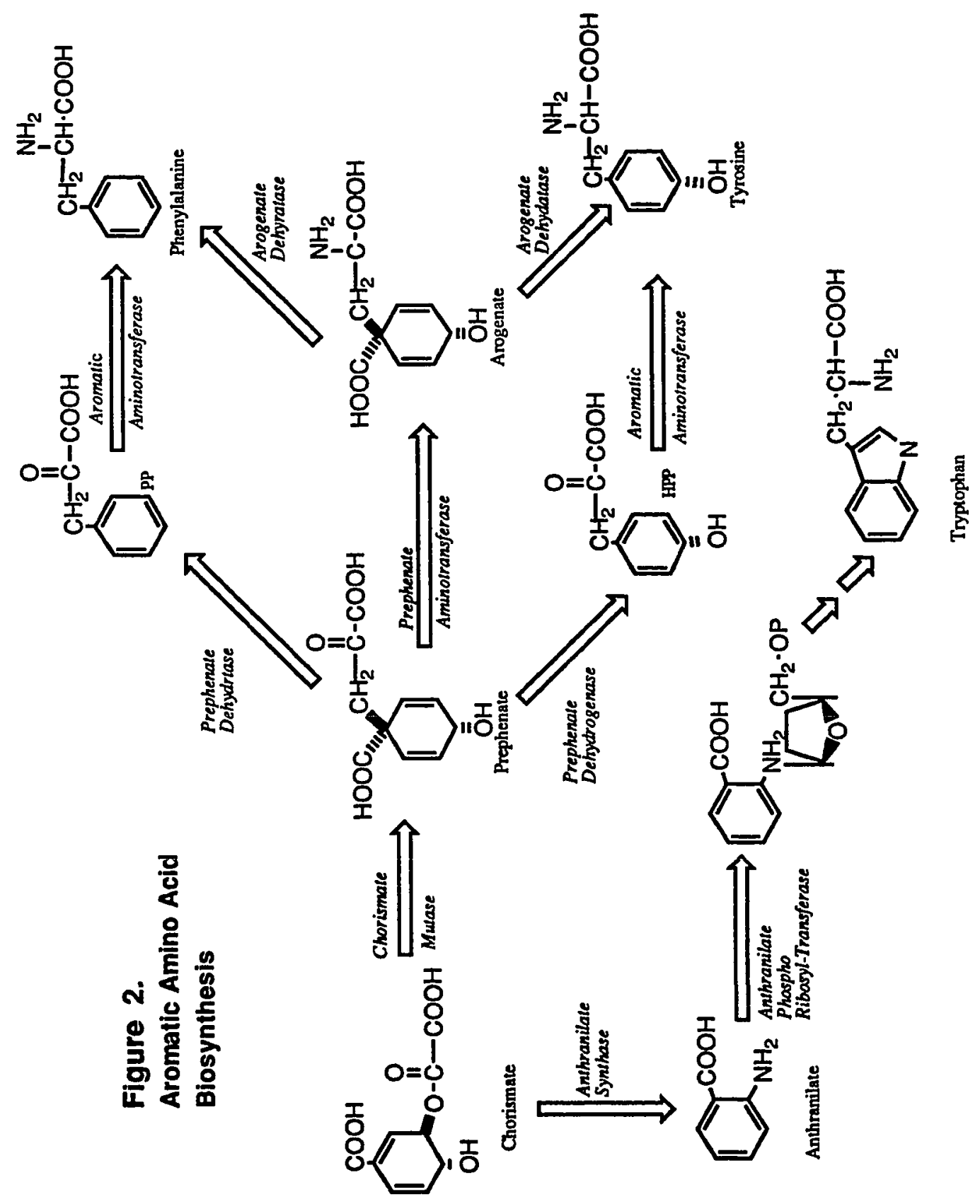


with the most common number being two (Singh, et al, 1990). The appearance of a single form may be due to loss of an unstable form during isolation, or inadequate chromatographic resolution. Where diversity was reported, there was no apparent correlation between morphology and the number of isoforms of chorismate mutase found in a particular plant species (Singh, et al, 1986). One particular dicot species may exhibit only one enzyme whereas another related species may show two or more isoforms of chorismate mutase. Not only are differences in the number of chorismate mutase apparent in plants but kinetic, physical and immunological properties were also demonstrated to vary between isoforms, whether from the same or from different species (Singh, et al, 1986).

In the most common case, where two isozyme are present, isozyme are classified on the basis of their subcellular location and regulatory properties. One form, designated CM-1, is plastidic and is found mainly in the chloroplast and proplasts (Connelly, 1986). This isoform is sensitive to regulatory control by the three aromatic amino acids end products. Tyrosine and phenylalanine, the ultimate end products of the chorismate mutase branch of the shikimate pathway are feedback inhibitors of the CM-1 isoform. Tryptophan, the other aromatic amino acid produced in this pathway, acts as a strong allosteric activator. In some 
cases, such as with Sorghum bicolor, tryptophan is essential for this isoform's activity. Because of its tight allosteric control $\mathrm{CM}-1$ has often been referred to as the regulated form of chorismate mutase. All plants investigated contain a regulated isoform. In most plants, a second form, designated $\mathrm{CM}-2$, was found as a cytosolic enzyme which is insensitive to the aromatic amino acids. The only report of regulatory control of $\mathrm{CM}-2$ was in Nicotinana silvestris, where $\mathrm{CM}-2$ was inhibited by caffeic acid, a metabolic secondary product of the shikimate pathway (Goers and Jensen, 1984).

It is difficult to distinguish the exact functions of these chorismate mutase isoforms. On the basis of their subcellular location and regulatory control, one group has postulated the existence of two complete pathways for the aromatic biosynthesis within the plant cell, one in the chloroplast and the other in the cytosol (Goers and Jensen, 1984). The chloroplastic pathway was hypothesized to be specialized for amino acid synthesis. The cytosolic pathway was thought to support the chloroplastic pathway and participate in the synthesis of secondary products. Physiological and enzymologic data support the notion that a complete shikimate pathway is present in the chloroplast. However, there is insufficient evidence to support the existence of a separate pathway in the cytosol (Singh, et 
a1, 1990). Although the dual pathway hypothesis has a sound basis in logic and may prove true, a thorough investigation of the properties and subcellular locations of chorismate mutase isoforms must be done before one can arrive at a complete picture of the involvement of these enzymes in cellular activity.

C. Bacterial Chorismate Mutases

In microorganisms, chorismate mutase has also been observed to exhibit diversity between species. In Escherichia coli two bifunctional enzymes have been isolated and found to exhibit both chorismate mutase and prephenate dehydratase or dehydrogenase activity, see figure 2, (Hudson, 1984; Calvin Ma and Davidson, 1985). Bacillus subtilis and Streptomyces aurefaciens, on the other hand contain a monofuntional enzyme capable of catalyzing only the chorismate mutase reaction (Goerisch, et al, 1973; Lleuellyn, et al, 1980). Although both species contained monofunctional enzymes, their regulatory properties differed. Chorismate mutase from $B$. subtilis was inhibited by prephenate but insensitive to the aromatic amino acids, whereas the chorismate mutase from $S$. aurefaciens was unregulated. Yeast (Saccharomyes cerevisiae) also exhibit monofunctional chorismate mutase (Schnmidheini, et al, 
1989). This particular organism's regulatory control is unique among microorganisms in that it is feedback inhibited by tyrosine and strongly activated by tryptophan.

What is particularly intriguing is that although these microbial chorismate mutases catalyze the same reaction, pair wise alignment of their amino acid sequences showed no significant homology (Schmnidheini, et al, 1989). This would imply that an unusually wide variety of primary structures can serve as an effective catalyst for the chorismate conversion to prephenate. This notion is supported by the observation that antibodies raised against hapten resembling the proposed transition state of the chorismate mutase reaction had catalytic chorismate mutase activity (Hilvert, et al, 1988; Jackson, et al, 1988). Despite the apparent fiexibility in the structure of the enzyme, there is strong evidence to suggest that the catalytic conversion of chorismate can only undergo one mechanistic route to prephenate.

D. Chorismate-Prephenate Reaction

The mechanistic route for the enzymatic conversion of chorismate to prephenate has been thoroughly studied using microbial enzymes. The isomerization of chorismate to prephenate is perhaps the only example of an enzymatically 
catalyzed claisen rearrangement in which chorismate undergoes a 3,3 sigmatropic shift (see Figure 3). Interestingly, this reaction occurs quite readily under nonenzymatic conditions in neutral aqueous solution at $37 \circ \mathrm{C}$. However, enzymatically, the rate of reaction is enhanced over two million fold (Andrews, et al, 1973). Isotopic labelling studies, employed to study the mechanistic intermediates involved in this rather intriguing reaction, indicate that the favored intermediate conformation involved in this conversion is a chair-like structure of chorismate (Copley and Knowles, 1987; Guilford, et al, 1984). In addition, there is strong evidence to suggest that chorismate mutase does not chemically participate in the reaction and that the rate enhancement is primarily due to the enzyme's role in stabilizing the chair-like geometry of chorismate (Andrews, et al, 1979).

Transitional conformations of substrate during catalysis often reflect the interactive groups that may participate at the active site of an enzyme. The most likely features of chorismate that may be involved in stabilizing its transition state are the positions of the hydroxyl and the carboxyl moieties, since these groups are capable of forming strong bonds with suitable partners. Possible bonds formed between these groups and various residues along the active site may be ionic bonding of the 


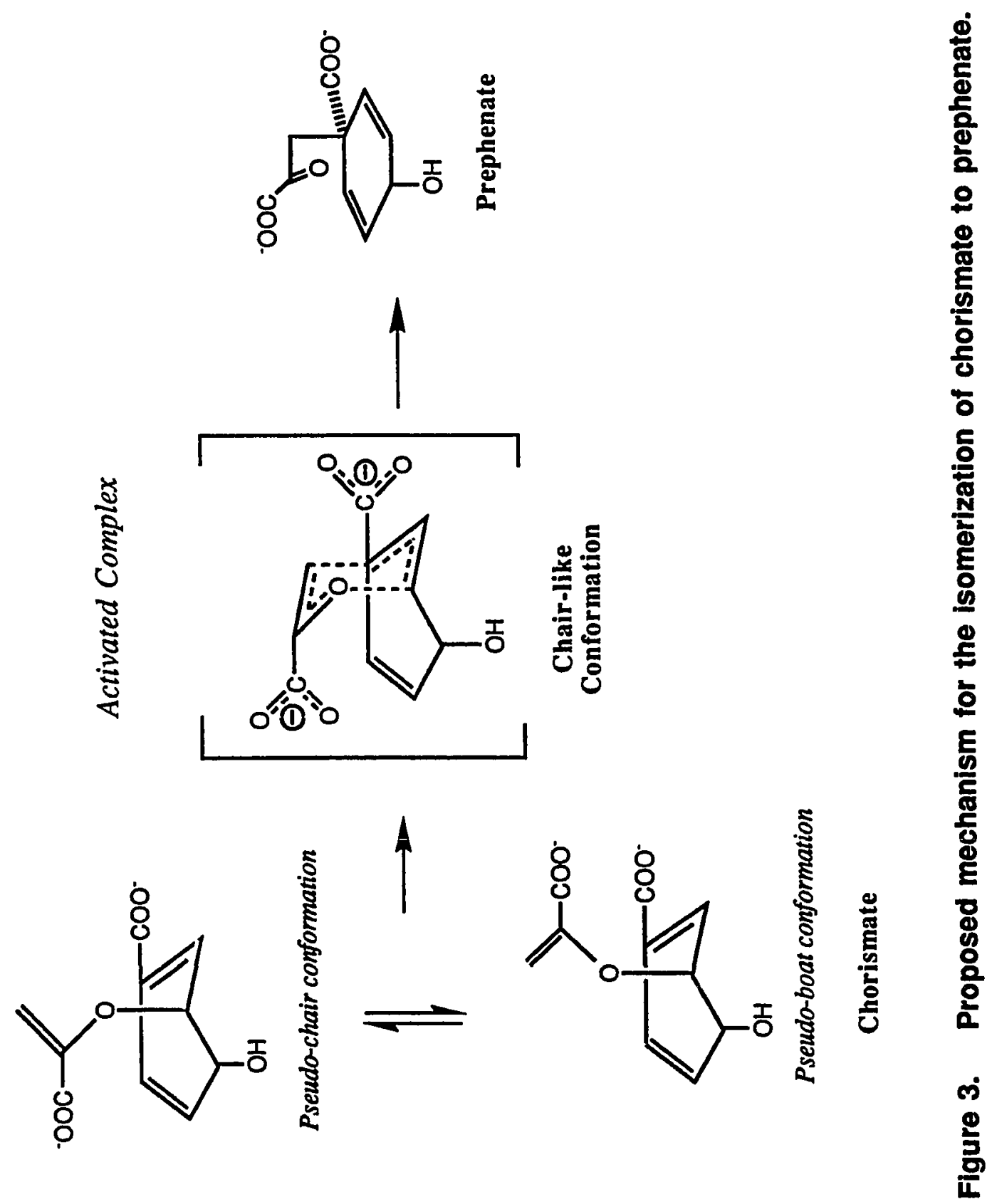


carboxyl groups and hydrogen bonding of the hydroxyl moiety. There have been no attempts to identify which specific amino acids may be involved in catalysis or binding at the active site of chorismate mutase in higher plants. A logical approach would be to compare amino acid sequence homologies between plant and microbial mutases. However, this is clearly not yet possible since no research has been done on the molecular characteristics of chorismate mutase from plants. Much of this problem stems from the fact that plant chorismate mutase has never been purified to homogeneity.

E. Proposed Research

As mentioned earlier, Sorghum bicolor is noted for its production of cyanogenic glycosides, secondary metabolites of the shikimate pathway. Production of these compounds were typically observed at high concentration during germination. Therefore, it is reasonable to assume that enzymes of the shikimate reactions are also in high abundance during the early growth periods of this plant species. Two isoforms of chorismate mutase have been observed in equal amounts from etiolated Sorghum bicolor, a regulated form and an unregulated form (Singh, et al, 1986). Both isoforms fit the classification scheme of plant 
chorismate mutases in that the regulated form (CM-1) is chloroplastic and is tightly regulated by the three aromatic amino acids (inhibited by L-tyrosine and L-phenylalanine but activated by I-tryptophan). The unregulated form on the other hand is cytosolic and is not affected by any shikimate metabolite. In justifying the biorational approach in developing target compounds for herbicidal action, only the regulated form, $\mathrm{CM}-1$, will be studied.

In this dissertation a scheme to purify $\mathrm{CM}-1$ to homogeneity from Sorghum bicolor has been developed. Kinetic, $\mathrm{N}$-terminal sequencing and amino acid composition data for this isoform have also been obtained. Determination of the amino acids that may be involved in the active site of $\mathrm{CM}-1$ is based on the transition state of chorismate. The positions and negative charges of the carboxyl groups of chorismate, suggested the possibility of two arginine residues residing along the active site as part of the stabilizing factors for the activated complex. The negatively charged carboxyl groups and the positively charged guanidino groups of arginine may allow weak ionic interaction to occur between these moieties. A schematic representation illustrating a proposed active site is shown in scheme 2. In this schematic drawing, two arginine residues are positioned along the catalytic site in such a way that ionic bonding between the guanidino groups of 
arginine and the carbonyl groups of chorismate occurs. Modification experiments with phenylglyoxal were used as a means of determining if the guanidino group of arginine is involved in stabilizing this intermediate. 


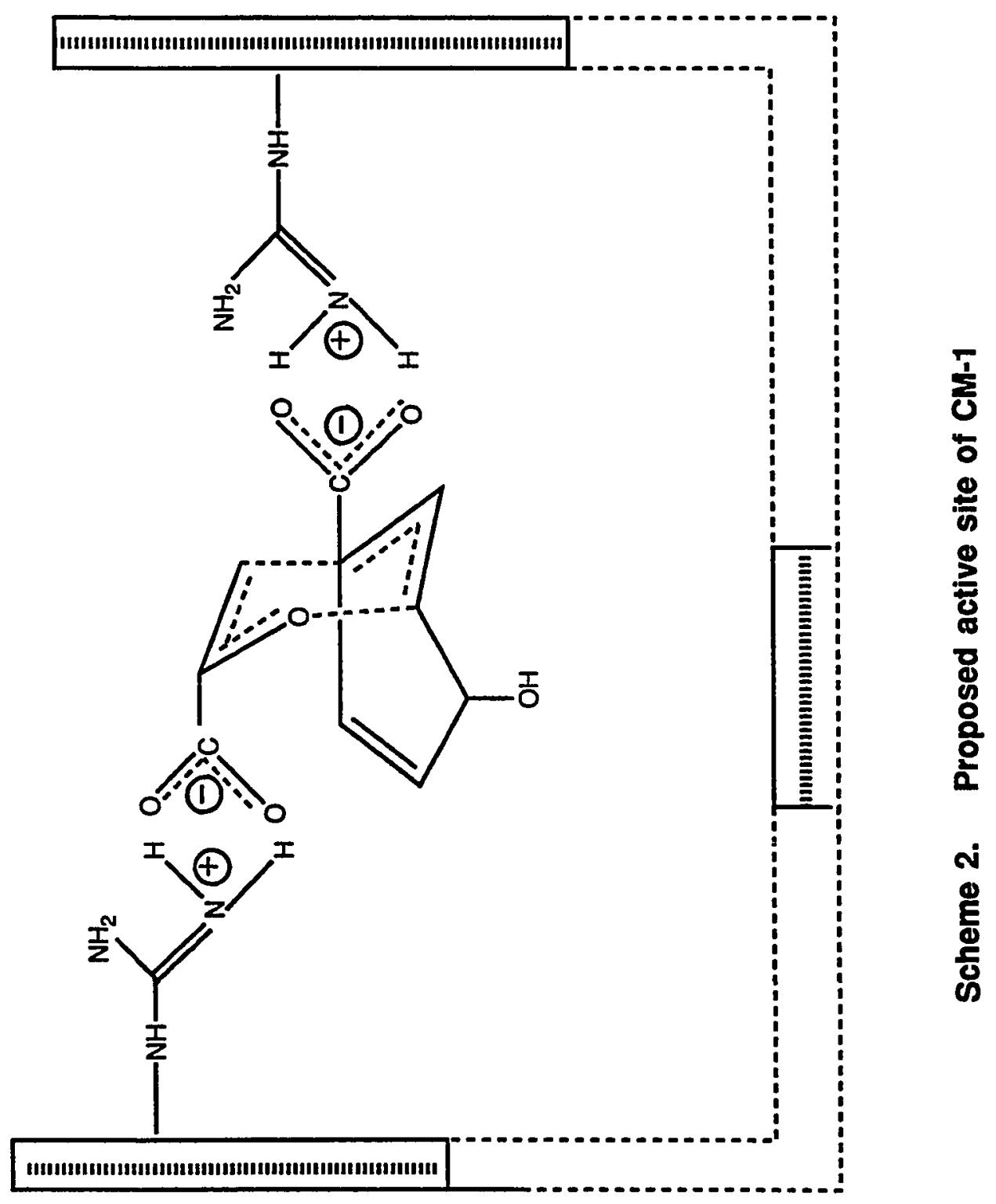


II. Materials

Tris-Base, Chorismate, Tris-HCl, NaOH, 2-mercaptoethanol, EDTA, glycine , KCl, L-Tryptophan, potassium phosphate (dibasic), glycerol, BSA (faction V), ethylene glycol, pyrophosphate (tetrasodium), L-arginine, 25\% glutaraldehyde, silver nitrate, sodium carbonate, and Sephadex G-25 course were purchased from Sigma (St. Louis, Mo). PM-10 membrane and Centricon 10 were purchased from Amicon (Danver, Mass.). Sephadex G-25 superfine, PD-10 columns and Phast system $12.5 \%$ homogenous SDS gels were purchased from Pharmacia (Piscataway, NJ). Actigel A was purchased from Sterogene Biochemicals (San Gabriel, CA). Bio-Rad protein dye was purchased from Bio-Rad (Richmond, CA). Cheesecloth grade 10 and 50 were both purchased from Arthur H. Thomas Cp. (Philadelphia, Pa). Sorghum bicolor, Trudan 8 was obtained from Northrup King (New Deal, Texas). Specially made silver stain molecular weight markers were purchased from Diversified Biotech (Newton Centre, MA). Whatman DE-52, Whatman GF/A membrane, ethylene glycol and acetonitrile were purchased from VWR (Sunnyvale, CA). p-Hydroxyphenylglyoxal was purchased from Pierce (Rockford, II) . Ammonium sulfate was purchased from Schwarz/Mann (Cambridge, MA). Malic anhydride was purchased from Matheson Coleman and Bell (Norwood, Ohio). Aquapore BU-300 
C4 column was purchased from Alltech Ass. Inc. (Deerfield, IL). 1-Methyl DL-tryptophan, tryptamine, 7-methyl-tryptophan, indole, abrine and 3-indole propionic acid were purchased from Aldrich (Milwaukee, WI).

III. Methods

\section{A. Assay}

Chorismate mutase activity was measured by determining its end product, prephenate, after acid conversion to phenylpyruvate. The amount of phenylpyruvate produced was detected and measured at $320 \mathrm{~nm}$ using its extinction coefficient of 17,500 $\mathrm{M}^{-1} \mathrm{~cm}^{-1}$ (Gibson and Gibson, 1963). Standard reaction mixtures contained $50 \mathrm{mM}$ buffer and 0.25 $\mathrm{mM}$ chorismate in a final volume of $0.5 \mathrm{ml}$. Chorismate was analyzed $92 \%$ pure by HPLC on reverse phase C-18 column. The major contaminant was analyzed to be 3\% p-benzoic acid, at $100 \mathrm{mM}$ this compound had no effect upon chorismate mutase from Sorghum bicolor activity (data not shown). Neither prephenate nor phenylpyruvate was detected. The buffers used for enzyme assay were glycine, $\mathrm{pH} 9.0$ for $\mathrm{CM}-1$ activity and Tris-HCl, $\mathrm{pH} 7.5$ for $\mathrm{CM}-2$ activity. Tris-HCl $\mathrm{pH} 8.0$ was used when both activities were present (Connelly, 1986). The reaction was started by the addition of enzyme and 
incubated at room temperature. Subsequently, after a given time interval, the reaction was stopped with 100 ul of $6 \mathrm{~N}$ HCl. After stopping the reaction, it was allowed to stand for 10 minutes to complete acid conversion of prephenate to phenylpyruvate, at which point $0.4 \mathrm{ml}$ of $4 \mathrm{~N} \mathrm{NaOH}$ was added. Absorbance at $320 \mathrm{~nm}$ was measured immediately against a $1 \mathrm{~N}$ NaOH blank.

Controls were prepared to correct for absorbance resulting from factors other than enzyme activity. Controls were prepared by adding $6 \mathrm{~N} \mathrm{HCl}$ prior to the enzyme. These controls were then subjected to the same experimental conditions as those with enzymatic activity. True absorbance values due to enzymatic activity were equated to the difference between the experimental and the control. One unit of enzyme was equal to the production of 1 nmol phenylpyruvate/min.

\section{B. Enzyme Purification}

1. Plant Material

Sorghum seeds (Sorghum bicolor, Trudan 8) were soaked in aerated tap water for 24 hours before planting to insure uniform germination. Imbibed seeds were then spread into a 
uniform layer in plastic containers between two inches of vermiculite and a single layer of cheese cloth (grade 10). A wire mesh was then placed on top of the cheesecloth to hold the cloth down during germination. These plastic flats were wetted with tap water and placed in a dark chamber at room temperature to induce etiolated shoots. After approximately five days or after shoots were 3-5 inches in length, they were harvested and powdered in liquid nitrogen using a mortar and pestle. The powdered shoots were quickly transferred into plastic bags and stored at $-700^{\circ}$ until used.

\section{Extraction}

Approximately 200 grams of powdered etiolated sorghum shoots were extracted with $100 \mathrm{ml}$ of $100 \mathrm{mM}$ glycine, $\mathrm{pH} 9.0$, containing $0.1 \%$ 2-mercaptoethanol and $0.1 \mathrm{mM}$ EDTA. The ground mixture was then filtered through two layers of grade 50 cheese cloth and the filtrate was centrifuged at 13,000 rpm for 20 minutes in a DuPont Sorvall RC-5B. All subsequent purification steps were carried out at $0-4 \circ \mathrm{C}$.

\section{Sephadex G-25 Desalting}

The centrifuged supernatant was loaded by gravity feed 
onto a one liter bed of coarse Sephadex G-25 (4.8 x $57 \mathrm{~cm})$ equilibrated with $100 \mathrm{mM}$ Tris, $\mathrm{pH} 8.0$, containing $1 \mathrm{mM}$ tryptophan and $0.1 \%$ 2-mercaptoethanol. Elution was carried out at the same flow rate with equilibration buffer. Ten milliliter fractions were collected and assayed for chorismate mutase activity. All fractions containing activity were pooled and assayed for enzyme activity.

\section{DEAE-Cellulose Chromatography}

After desalting on G-25, the enzyme eluate was mixed for 30 minutes with 50 grams of Whatman DE-52 ion exchange material. This mixture was then transferred into a $400 \mathrm{ml}$ Amicon ultrafiltration unit containing a Whatman GF/A membrane, and washed with $500 \mathrm{ml}$ of $100 \mathrm{mM}$ Tris-HCl. The enzyme solution was allowed to pass through the ultrafiltration unit, leaving only the ion exchange matrix behind. The matrix was washed with $500 \mathrm{ml}$ of $100 \mathrm{mM}$ Tris, pH 8.0 containing $1 \mathrm{mM}$ Tryptophan and to remove unbound material. Elution and separation of $C M-1$ from $C M-2$ were achieved by two separate $\mathrm{KCl}$ washes of $500 \mathrm{ml}$ each. The first wash, which contained $0.1 \mathrm{M} \mathrm{KCl}$ in the wash buffer, eluted $\mathrm{CM}-2$. A second wash containing $0.5 \mathrm{M} \mathrm{KCl}$ eluted CM-1. Both eluate were precipitated by $60 \%$ saturated ammonium sulfate, redissolved in smaller volumes, and 
desalted on Sephadex PD-1C columns, equilibrated with $50 \mathrm{mM}$ Tris, $\mathrm{pH} 7.5$.

\section{Tryptophan Affinity Chromatography}

Preparation of the Actigel A matrix, an activated aldehyde-agarose, and coupling to tryptophan were performed as suggested by the manufacturer. Coupling was performed under neutral conditions using $0.1 \mathrm{M}$ potassium phosphate (dibasic), $\mathrm{pH} 7.5$ as coupling buffer. The amount of tryptophan bound to the matrix was measured by taking the absorbance at $280 \mathrm{~nm}$ and using tryptophan's extinction coefficient of $5600 \mathrm{M}^{-1} \mathrm{~cm}^{-1}$. After coupling tryptophan to Actigel A, the matrix was poured into a $1 \times 17 \mathrm{~cm}$ column and equilibrated with $50 \mathrm{mM}$ Tris, $\mathrm{pH} 7.5$.

Concentrated $\mathrm{CM}-1$ which was separated by $\mathrm{DE}-52$

chromatography was then loaded onto the Actigel-tryptophan column at a flow rate of $0.25 \mathrm{ml} / \mathrm{min}$. The column was washed with $50 \mathrm{ml}$ of equilibration buffer and eluted with a $\mathrm{pH}$ gradient of 7.5 to 10.0 with $100 \mathrm{ml}$ of equilibration buffer in the mixing chamber and $100 \mathrm{ml}$ of $100 \mathrm{mM}$ Tris, $\mathrm{pH} 10.0$ containing $0.2 \mathrm{mM}$ L-tryptophan in the reservoir. Five milliliter fractions were collected and assayed for $\mathrm{CM}-1$ activity. Fractions with activity were pooled and concentrated using an Amicon ultrafiltration cell containing 
a PM-10 membrane.

\section{SDS Electrophoresis}

CM-1 purity was measured by SDS-PAGE. One milliliter of CM-1 purified from the Actigel-tryptophan affinity column was concentrated with an Amicon centricon 10 to a final concentration of $30 \mathrm{pmol} / \mathrm{ul}$. SDS electrophoresis was performed using the Pharmacia "Phastsystem." Four microliter of the concentrated enzyme solution was diluted with an equal part of sample buffer (1.5M Tris-HCL, $4 \%$ SDS, $20 \%$ glycerol, $0.01 \%$ bromophenol blue and $10 \%$

2-mercaptoethanol). Four microliter of the diluted preparation was loaded on a $12.5 \%$ homogenous SDS gel. Separation parameters were set as suggested by the manufacturer for 12.58 homogenous SDS gels: $70 \mathrm{Vh}, 250 \mathrm{~V}$, $10.0 \mathrm{mM}, 3.0 \mathrm{~W}$ and $150 \mathrm{C}$. Two microliter of molecular weight markers, made specially for silver staining, was also prepared in $2 \mathrm{ml}$ of sample buffer and loaded on the gel. Total separation time took 30 minutes, after which the gel was silver stained using a set of programmed methods indicated by the manufacturer. 


\section{Protein Assay}

\section{Protein Dye}

Bio-Rad protein dye was used as a colorimetric assay to measure protein concentration. To detect small concentrations of protein (less than $25 \mathrm{ug} / \mathrm{ml}$ of protein), the microassay procedure was used. Bio-Rad protein dye 1200 ul) was placed in $10 \times 75 \mathrm{~mm}$ test tubes; 800 ul of protein solution was then added and thoroughly mixed. After mixing, each sample was allowed to sit at room temperature for 5 minutes, at which point the absorbance at $595 \mathrm{~nm}$ was determined. Protein standard curves were prepared by dissolving known amounts of bovine serum albumin (BSA) in the same buffer as the protein sample. A plot of the ug protein versus absorbance at $595 \mathrm{~nm}$ was made. The protein concentration for each sample was determined by extrapolating its absorbance to ug protein based on the derived standard curve.

2. Absolute Protein Determination at 235 and $280 \mathrm{~nm}$

The difference in absorbance at 235 and $280 \mathrm{~nm}$ is a simple method to measure absolute protein concentration 
$(\mathrm{mg} / \mathrm{ml})$. Difference between these absorbance is directly proportional to the number of peptide bonds in the sample (Whittaker and Gramum, 1980). A straightforward equation was used to convert this difference to $\mathrm{mg}$ protein/ml;

Equation 1:

(absorbance at $235 \mathrm{~nm}$ - absorbance at $280 \mathrm{~nm}) / 2.51=$ $\mathrm{mg} / \mathrm{ml}$ protein

where the factor 2.51 is the difference between the average measured extinction coefficient of a number of proteins at 235 and $280 \mathrm{~nm}$ (Whitaker and Gamum, 1980). In order to determine accurately the absorbance of small quantities of enzyme, 50 ul of protein sample was directly injected without the use of a column into the flow cell of a HewlettPackard $1050 \mathrm{UV}$ detector using an autoinjector. Instrument parameters were as follows: a flow rate of $1.0 \mathrm{ml} / \mathrm{min}$, Milli-Q water was used as the mobile phase, and peak integration was set in counts of peak height. Two separate injections were performed per sample and analyzed at the two wavelengths. A modified version of the first equation was used to convert units of $\mathrm{mv}$ to $\mathrm{mg}$ protein per $\mathrm{ml}$. 
Equation 2 .

(counts at $235 \mathrm{~nm}$ - counts at $280 \mathrm{~nm}$ ) $\times 0.125 \mathrm{uV} /$ count $2 \mathrm{mAU} / \mathrm{uV} \times \mathrm{AU} / 1000 \mathrm{mAU} \times 1 / 0.6 \times 1 / 2.51=\mathrm{mg}$ protein $/ \mathrm{ml}$

To illustrate the effectiveness and limitations of sensitivity of this technique, a stock solution containing $6.545 \mathrm{mg} / \mathrm{mI}$ of bovine serum albumin in $50 \mathrm{mM}$ pyrophosphate buffer $\mathrm{pH} 11.3$ was diluted to various protein concentrations in buffer and directly injected into the Hewlett-Packard system. Protein concentration was determined using equation 2 .

\section{Preparation of $\mathrm{CM}-1$ for Amino Acid Analysis and N-terminal Sequencing}

Preparation of $\mathrm{CM}-1$ for amino acid analysis was performed on an Hewlett-Packard 1050 HPLC system using a $\mathrm{BU}-300 \mathrm{C}-4$ reverse phase column $(10 \mathrm{~cm} \times 2.1 \mathrm{~mm} \mathrm{ID}, 7$ micron) purchased from Brownlee Labs. The integrator was set at 0.002 absorbance full scale and the chart speed at $0.2 \mathrm{~cm} / \mathrm{sec}$. Prior to injection, $1 \mathrm{ml}$ of $\mathrm{CM}-1$ purified from the Actigel-tryptophan affinity column was concentrated to 100 ul using an Amicon centricon 10. The filtrate from this concentration step was saved and injected separately on the 
reverse phase column to determine inherent buffer peaks. One hundred microliter of each sample was injected. Elution parameters are shown in Table I. Enzyme peaks were collected and analyzed for $\mathrm{N}$-terminal sequence and amino acid composition.

Prepared $\mathrm{CM}^{-1}$ was given to the biochemistry department of Sandoz Crop Protection for $\mathrm{N}$-terminal sequencing and amino acid analysis. Sequence analysis was employed on Applied Biosystems model 477A pulsed liquid phase protein sequencer equipped with a model $120 \mathrm{~A}$ on line phenylthiohydantoin amino acid analyzer. Amino acid analysis was performed on Hewlett-Packard Amino Quant system.

\section{E. Tryptophan Analogues}

As mentioned previously, tryptophan is an essential activator for $\mathrm{CM}-1$ in Sorghum bicolor. To elucidate the structural features of tryptophan involved the activation of this enzyme, selected analogues of tryptophan (see page 47) were substituted in its place and incubated with $\mathrm{CM}-1$. A set of five reaction vials were made per tryptophan analog. Each vial contained $50 \mathrm{mM}$ glycine $\mathrm{pH} 9.0,20 \%(\mathrm{v} / \mathrm{v})$ ethylene glycol, $0.03 \mathrm{ug}$ of $\mathrm{CM}-1$ solution purified on the actigel-tryptophan column and 20 uM tryptophan analog in a 


\section{Table 1. HPLC Parameters for Preparation of Enzyme for N-terminal Sequence.}

Flow rate: $0.5 \mathrm{ml} / \mathrm{min}$

Detection: $280 \mathrm{~nm}$

Running Conditions

Minutes

$$
\% \text { Water }
$$

40

10

10
$\%$ Acetonitrile

20

60

60
$\% 0.25 \%$ TFA

40

30

30 
final volume of $500 \mathrm{ul}$. The vials were then assayed for chorismate mutase activity as described above. The final concentration of chorismate was $0.125 \mathrm{mM}$. Controls were included in which acid was added prior to adding chorismate. The degree of activation by analogues of tryptophan was expressed as a percentage of the activation by tryptophan.

F. CM-1 Modification

1. Comparative Analysis of Lysine and Arginine Modification

Semipure CM-1 prepared from DE-52 matrix was desalted on Sephadex PD-10 columns using $50 \mathrm{mM}$ pyrophosphate buffer containing $0.2 \mathrm{mM}$ tryptophan. One milliliter aliquot of this CM-1 preparation was incubated with either HPGO or maleic anhydride. Three reaction vials were made as follows;

Vial 1 (control): $1 \mathrm{ml}$ of $\mathrm{CM}-1$ solution in pyrophosphate buffer.

Vial 2: $1 \mathrm{ml} \mathrm{CM-1} \mathrm{containing} \mathrm{a} \mathrm{final} \mathrm{concentration} \mathrm{of}$ $6 \mathrm{mM}$ HPGO in pyrophosphate buffer.

Vial 3: $5.0 \mathrm{ml}$ of $\mathrm{CM}-1$ containing a final concentration of $6 \mathrm{mM}$ maleic anhydride in pyrophosphate buffer.

Vial 1 and 2 were incubated at $25^{\circ} \mathrm{C}$ in a covered water bath. 
Vial 3 was kept at $21^{\circ} \mathrm{C}$ with constant stirring; $\mathrm{pH}$ was monitored and kept at $\mathrm{pH} 9.0$. Two time points were taken, 30 and 60 minutes. At the end of each time point, an aliquot of each reaction vial was removed and desalted on PD-10 columns. The columns were washed and eluted with 50 mM pyrophosphate buffer. Eluate were collected and assayed for $\mathrm{CM}^{-1}$ activity. Assay buffer used was $50 \mathrm{mM}$ pyrophosphate buffer, pH 9.0 containing $0.2 \mathrm{mM}$ tryptophan. Extent of inactivation by both modifiers were compared to the control activity at each corresponding time point. Percent activity remaining after each time point was measured.

2. Inactivation of $\mathrm{CM}-1$ with HPGO

Semipure $C M-1$ prepared from $D E-52$ matrix containing at least $6.0 \mathrm{nmol}$ phenylpyruvate/minute/ml was subjected to arginine modification by HPGO. Prior to incubation with HPGO, CM-1 was desalted on a Sephadex PD-10 column with 50 $\mathrm{mM}$ pyrophosphate buffer, $\mathrm{pH}$ 9.0. The concentration of HPGO used was $6.4 \mathrm{mM}$ in $50 \mathrm{mM}$ pyrophosphate buffer. In addition, inactivation by this modifier was observed in the presence or absence of $0.2 \mathrm{mM}$ tryptophan and $1.0 \mathrm{mM}$ chorismate. Five reaction vials were prepared as follows: 
Vial 1 (control): $2.0 \mathrm{ml}$ of $\mathrm{CM}-1$ solution containing approximately $0.8 \mathrm{mg}$ protein in $50 \mathrm{mM}$ pyrophosphate buffer containing $0.2 \mathrm{mM}$ tryptophan.

Vial 2 (Enzyme + chorismate + HPGO + Tryptophan): 2.0 $\mathrm{ml}$ CM-1 solution in a final concentration of $1 \mathrm{mM}$ chorismate, $0.2 \mathrm{mM}$ tryptophan and HPGO.

Vial 3 (Enzyme + chorismate + HPGO): same as vial 2 but the reaction was carried out in the absence of tryptophan.

Vial 4 (Enzyme + HPGO + tryptophan): same as vial 2 but the reaction was carried out in the absence of chorismate.

Vial 5 (Enzyme + HPGO) : same as vial 2 but tryptophan and chorismate was absent in the reaction mixture.

Each reaction vial was placed in a covered water bath set at $25^{\circ} \mathrm{C}$ and five consecutive time points were taken $10,5,20$, 40 and 60 minutes). At the end of each time interval, a 400 ul aliquot of each reaction vial was removed and desalted on Sephadex PD-10 columns with $50 \mathrm{mM}$ pyrophosphate buffer and subsequently assayed for CM-I activity. The assay buffer consisted of $50 \mathrm{mM}$ pyrophosphate buffer containing $0.2 \mathrm{mM}$ tryptophan and $0.125 \mathrm{mM}$ chorismate. The extent of inactivation was measured as percent activity remaining after each time point as compared to the control's activity at the corresponding time interval.

A similar procedure using HPGO to modify purified CM-1 was performed. CM-1 purified from tryptophan affinity chromatography was desalted on a Sephadex PD-10 column using 
pyrophosphate buffer. A final concentration of $0.2 \mathrm{mM}$ HPGO was added to the enzyme solution. A control containing only the enzyme in pyrophosphate buffer was also made. Both control and $\mathrm{CM}-1$ with HPGO were placed in a covered water bath set at $25{ }^{\circ} \mathrm{C}$. At subsequent time points of $0,10,20$, 40, 60 and 90 minutes, 400 ul of each reaction vial was desalted on Sephadex PD-10 column equilibrated with pyrophosphate buffer, then assayed for CM-1 activity. Percent activity remaining based on control's activity at each corresponding time point were measured.

3. Quantitation of Number of Modified Arginine Residues

Quantitation of the number of modified arginine residues by HPGO is based on the formation of arginine-HPGO derivative. When formed on arginine residues within a protein, this highly conjugated molecule is detected spectroscopicaily at $340 \mathrm{~nm}$ and quantified using its molar extinction coefficient of $1.83 \times 10^{4} \mathrm{M}^{-1} \mathrm{~cm}^{-1}$ (Yamaski, et al, 1980) .

BSA was weighed and dissolved in $50 \mathrm{mM}$ pyrophosphate buffer. One milliliter of this stock solution was incubated in the dark at room temperature for one hour with 100 ul of $10 \mathrm{mg} / \mathrm{ml}(\mathrm{w} / \mathrm{v})$ HPGO dissolved in pyrophosphate buffer. One hundred microliter of $50 \mathrm{mM}$ pyrophosphate was added to a 
similar volume of BSA solution. This solution served as control. After one hour both solutions of BSA were desalted on Sephadex PD-10 columns using pyrophosphace buffer. Standard curves were subsequently made using these stock BSA solutions.

These stock solutions of modified BSA were used to construct standard curves correlating area counts obtained by an integrator with known amounts of BSA or known amounts of arginine-HPGO derivative within BSA. The concentration of arginine-HPGO per volume of BSA solution was obtained by measuring the absorbance at $340 \mathrm{~nm}$ and using its molar extinction coefficient given above. Aliquots of this modified BSA solution were then injected onto a superfine Sephadex G-25 column (25-150 u particle size) at a flow rate of $0.5 \mathrm{ml} / \mathrm{min}$. A plot of pmol arginyl-HPGo versus area counts was made. In addition, a protein standard curve using the unmodified BSA stock solution measured at $280 \mathrm{~nm}$ was also made in order to correlate area counts to known amounts of protein. Using the method discussed in the protein assay section, protein concentration for very dilute protein solutions can be determined by extrapolating its area counts to moles of protein based on these derived standard curves.

An aliquot of homogenous $\mathrm{CM}-1$ was prepared by exchanging its buffer to that of $50 \mathrm{mM}$ pyrophosphate buffer 
using Sephadex PD-10. This prepared solution of $\mathrm{CM}-1$ was concentrated using the Amicon Centricon 10. A known volume of the concentrate was injected onto the Sephadex G-25 column and area count was measured at $280 \mathrm{~nm}$. Protein concentration was determined by extrapolating these values on the derived BSA standard curve.

This same prepared solution of $\mathrm{CM}-1$ was modified with HPGO in the presence and absence of its substrate, chorismate. The following reactions were made:

Vial 1 (control): 50 ul $\mathrm{CM}-1$ solution with 35 ul pyrophosphate buffer.

Vial 2: 10 ul of 60mM HPGO in pyrophosphate, $25 \mathrm{ul}$ $5 \mathrm{mM}$ chorismate in pyrophosphate and 50 ul $\mathrm{CM}-1$ solution.

Vial 3: $10 \mathrm{ul}$ of $60 \mathrm{mM}$ HPGO, 25 ul pyrophosphate buffer and 50 ul $\mathrm{CM}-1$ solution.

Each vial was incubated for one hour in the dark at room temperature, after which 25 ul of each sample was injected onto Sephadex G-25 column. The area count for each sample was measured and the total arginine-HPGO derivative was calculated based on the modified BSA standard curve and total protein concentration also obtained from the BSA protein standard curve. 
VI. Results

A. CM-1 purification

The purification protocol consisted of a three column process that results in a homogenous enzyme solution based on SDS-PAGE. This process takes as little as two days and has the flexibility for accepting large amounts of plant tissue for purification. The set of columns consisted of a Sephadex G-25 desalting column, Whatman DE-52 ion exchange material and a tryptophan affinity column. The purification scheme is shown in Table 2 .

A typical preparation consisted of 200 grams of 5 day old etiolated Sorghum bicolor shoots. Extraction was performed under basic conditions to maintain chorismate mutase's optimal pH conditions (Singh, 1986). Since phenolic compounds are often problematic in plant enzyme isolation, it was necessary to separate these small compounds from the enzymes by using Sephadex G-25 (Loomis, 1969). Not only does this separation technique remove unwanted phenolic, but also a majority of small UV absorbing compounds that may interfere with the enzyme assay. Because naturally occurring tryptophan is also separated from the bulk of the plant enzyme, it was necessary to include this 
$|\cdots$.

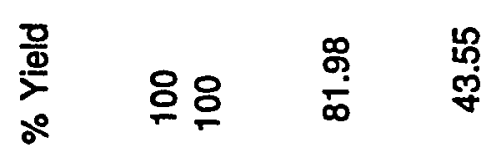

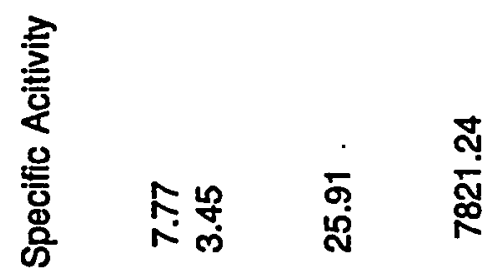

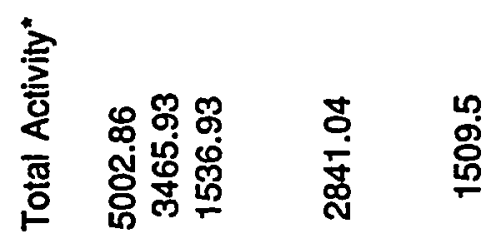

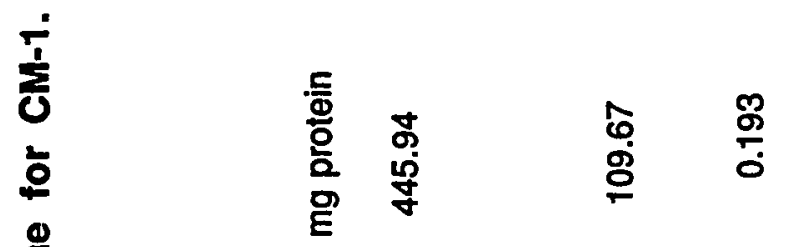

हू

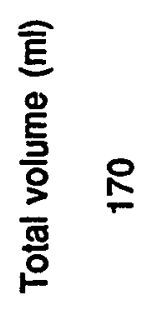

ำ

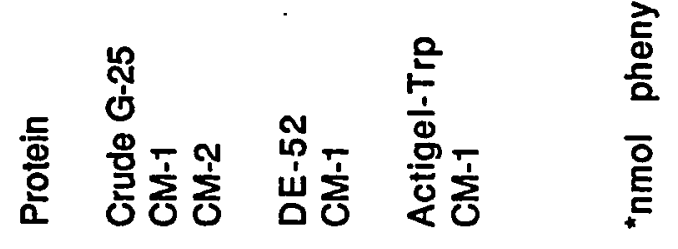


amino acid in the equilibration buffer to maintain $\mathrm{CM}-1$ activity.

CM-1 and CM-2 were separated by bulk separation using Whatman DE-52, an ion exchange matrix. This bulk method of separation omits the lengthy time required to load, wash and elute the enzymes, as in the earlier report (Singh, 1986). Flow rates of up to $10 \mathrm{ml} / \mathrm{min}$ were achieved and total separation time took less than one hour. Iarge volumes containing $\mathrm{CM}-1$ and $\mathrm{CM}-2$ obtained from this procedure were concentrated by precipitation with 60\% saturated ammonium sulfate. Desalting on PD-10 columns was performed in order to remove the ammonium salt as well as to remove tryptophan from the enzyme solution. Removal of tryptophan was required for the subsequent binding of $\mathrm{CM}-1$ to the tryptophan affinity column.

The Actigel A matrix was coupled to tryptophan's alpha-amino group. The coupling reaction is based on the formation of a Schiff-base and its reduction with sodium cyanoborohydride as shown in Figure 4. Typical protein and enzyme activity profiles from this affinity column are shown on Figure 5. The majority of protein did not bind to the column, and a large peak of $\mathrm{CM}-1$ activity was observed between $\mathrm{pH}$ 8-8.5. The pooled fractions within this $\mathrm{pH}$ range contained less then $4 \mathrm{ug} / \mathrm{ml}$ protein. A single band was observed on SDS-PAGE (Figure 6), corresponding to a 


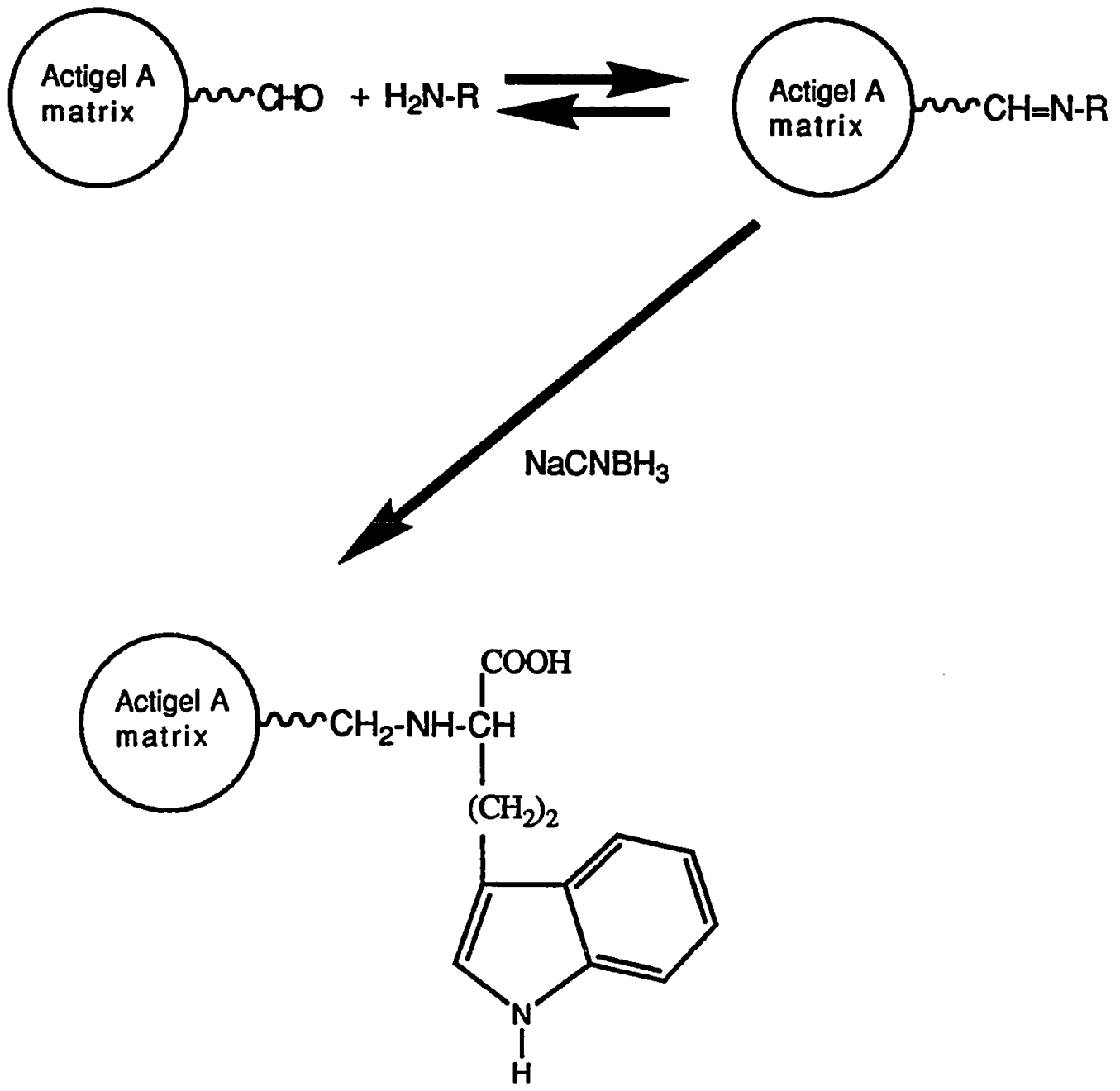

Figure 4. Coupling Reaction Between Actigel A and Tryptophan. 
10.0

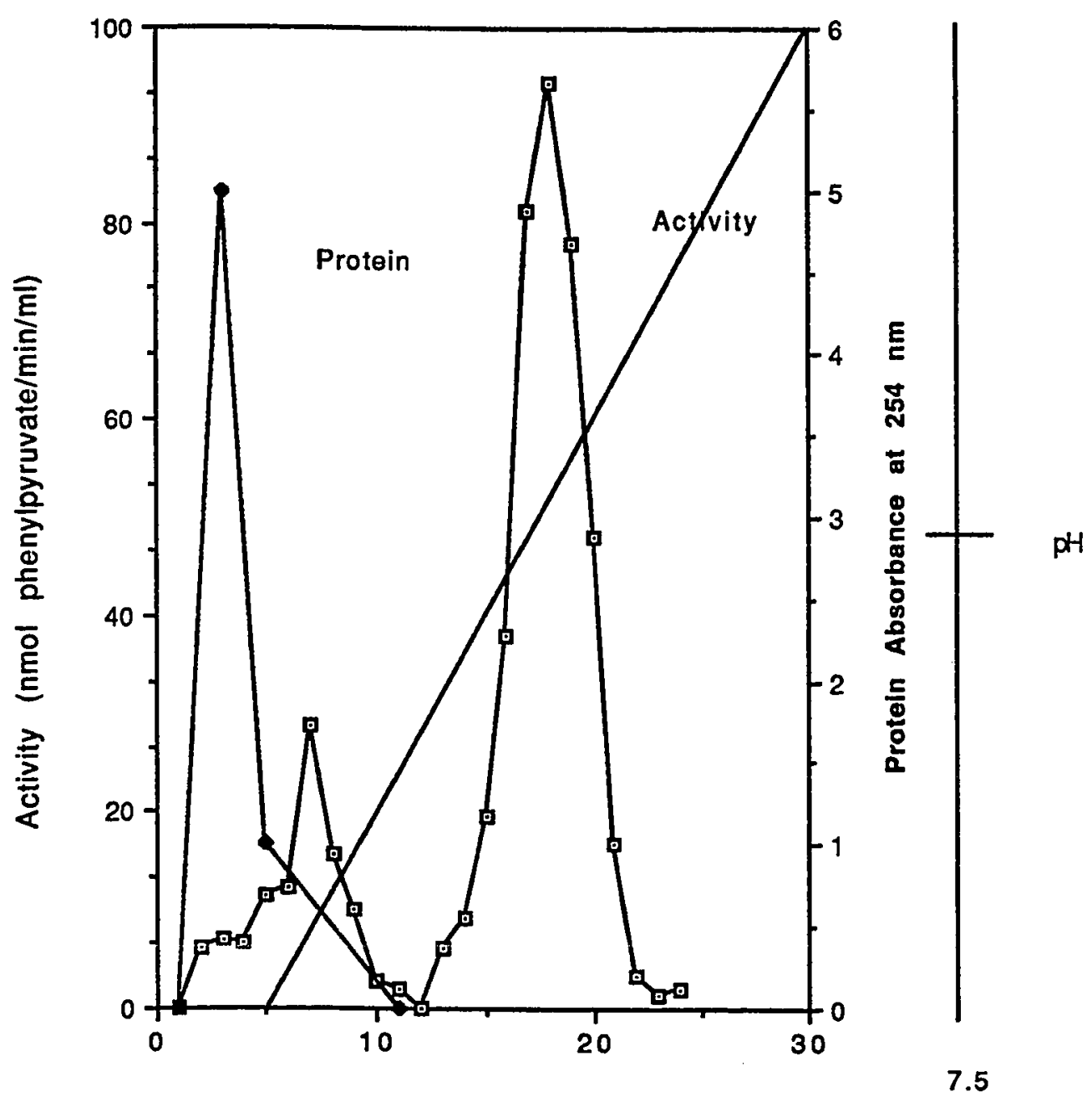

Fractions

Figure 5. Actigel-Tryptophan Affinity Column elution Profile. 
Figure 6. SDS-PAGE of Tryptophan-Actigel

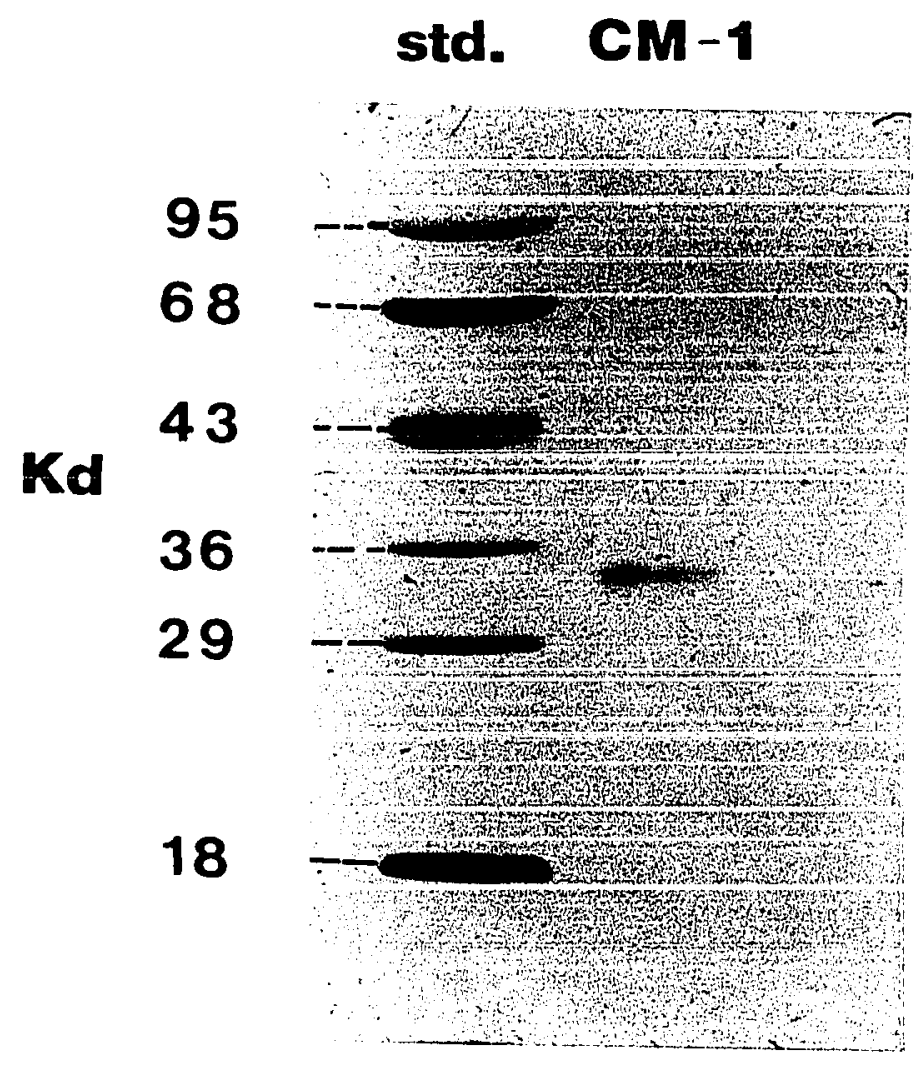


molecular weight of 34,000 daltons (Figure 7). These results indicate this affinity column's high selectivity for only $\mathrm{CM}-1$. All other proteins were easily removed during the wash step.

\section{B. Saturation Kinetics}

Activity of $\mathrm{CM}-1$ in Sorghum bicolor is highly dependent on availability of tryptophan. This dependency is exemplified by the fact that absence of this activator renders the enzyme inactive. For this reason, it was necessary to characterize the activation and to incorporate the effects of tryptophan into a study on substrate saturation kinetics.

The initial rate of the $\mathrm{CM}-1$ reaction was measured at $0.125 \mathrm{mM}$ chorismate and various concentration of tryptophan. The resulting activation curve (Figure 8) indicated half maximal activation, $A(0.5)$, at about 1.5 uM tryptophan and full enzymatic activity at 5-10 uM tryptophan. Saturation kinetics for chorismate were then determined at saturating (5 uM) and non-saturating ( 1 uM) concentrations of tryptophan. Saturating levels of tryptophan gave a hyperbolic saturation curve and a linear reciprocal plot yielding a $\mathrm{Km}$ value for chorismate of $0.446 \mathrm{mM}$ (Figure 9). 


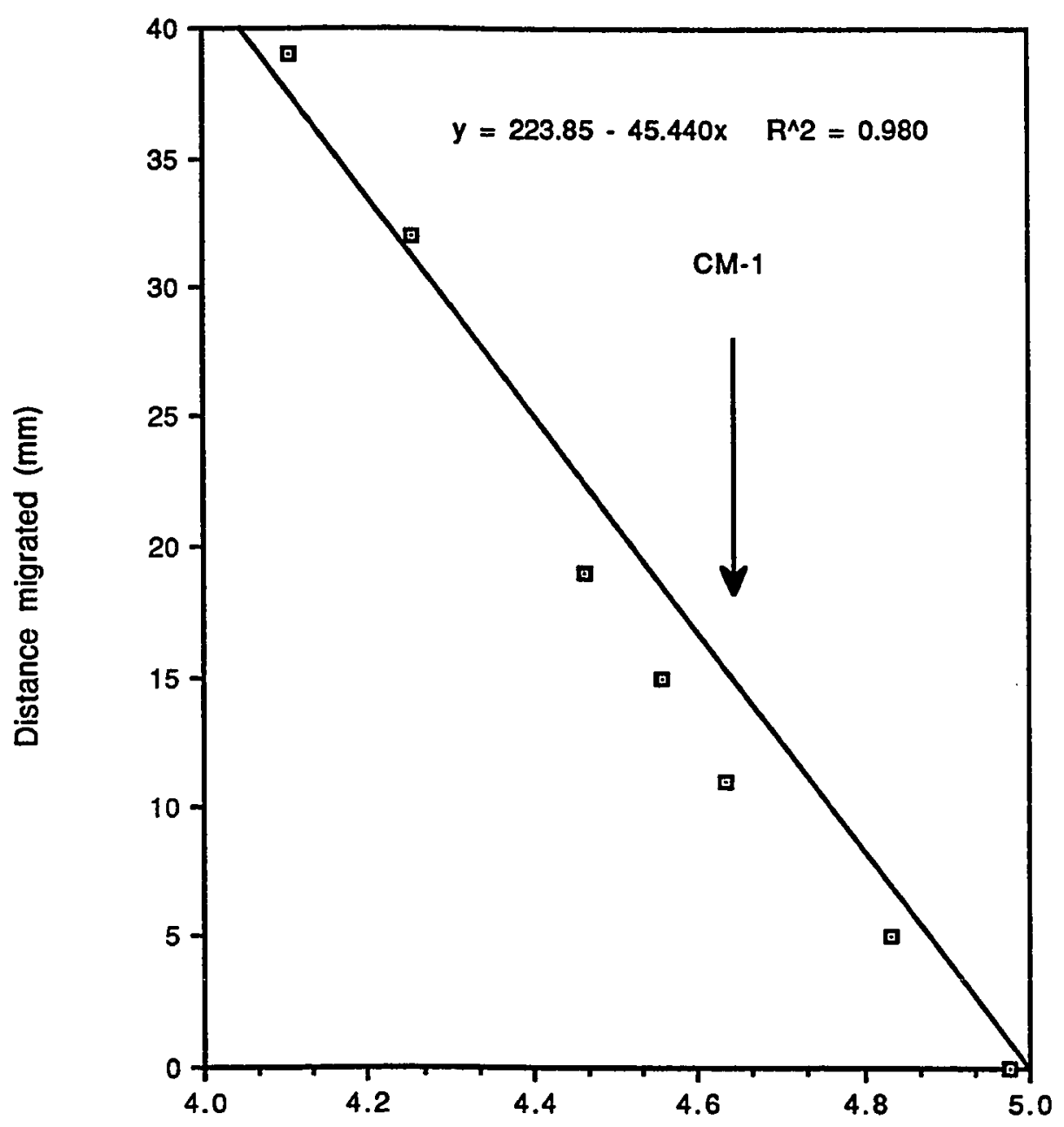

Log Molecular Weight

Figure 7. SDS-PAGE Molecular Standard Curve 


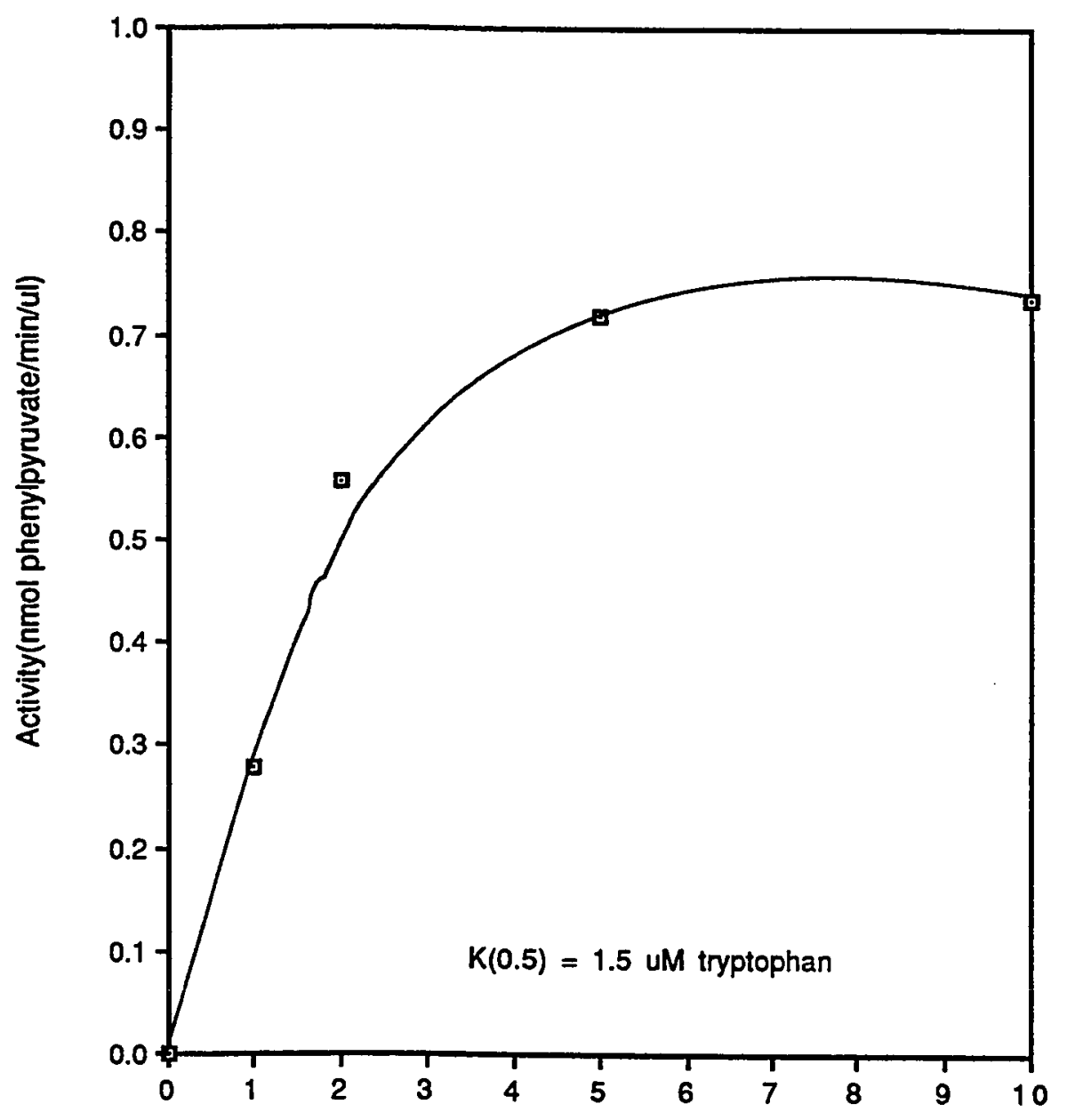

[Tryptophan] UM

Figure 8. Activation of CM-1 by Tryptophan 
At non-saturating levels of tryptophan, the not fully activated enzyme displayed a sigmoidal saturation curve and a $\mathrm{Km}$ value for chorismate of $2.58 \mathrm{mM}$. Vmax values were nearly identical for both concentrations of tryptophan. Vmax at 1 uM and 5 uM tryptophan were 1.47 and 1.33 respectively.

The degree of cooperativeness in substrate binding is illustrated using a Hill plot. A slope value of 1 was obtained for 5 uM tryptophan and a slope of 1.4 for 1 uM tryptophan. A slope value of 1 is indicative of hyperbolic kinetics, whereas slope values greater then 1 show positive cooperativeness. The Hill plot shown in Figure 10 illustrates the shift from saturating levels of tryptophan to high positive cooperativeness at low levels of tryptophan.

\section{Tryptophan Analogues}

To understand the structural features of tryptophan that may be involved in its binding and activation of $\mathrm{CM}-1$, selected tryptophan analogues were substituted in place of tryptophan and their potential to activate the enzyme was measured. The degree of activation was based on the percent activity of the enzyme induced by tryptophan at the same concentration. Purified $\mathrm{CM}-1$ was incubated with the tryptophan analogues shown in Table 3 . Several replicates 


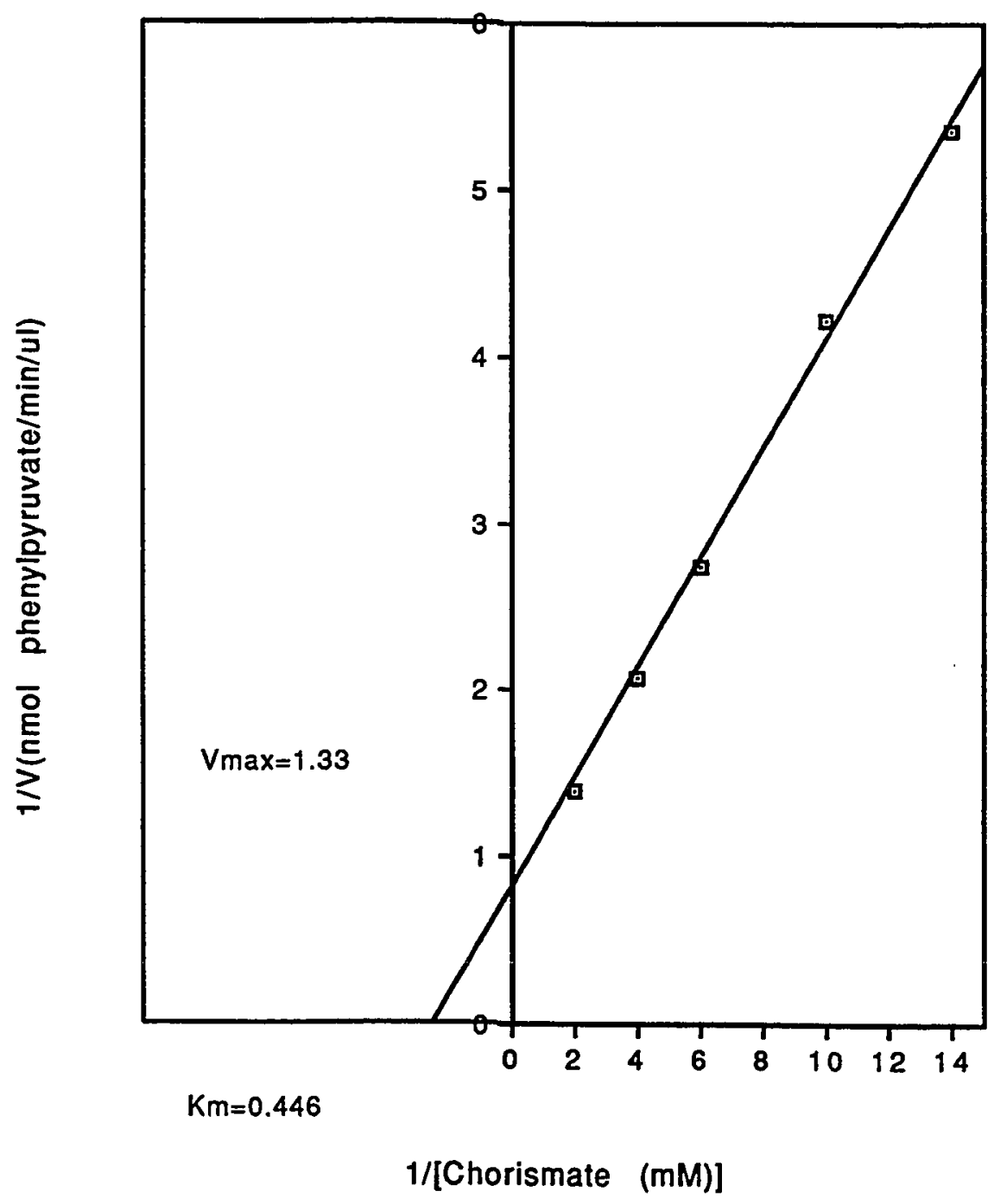

Figure 9. Reciprocal Plot of CM-1 Saturation by Chorimate at 5uM Tryptophan 


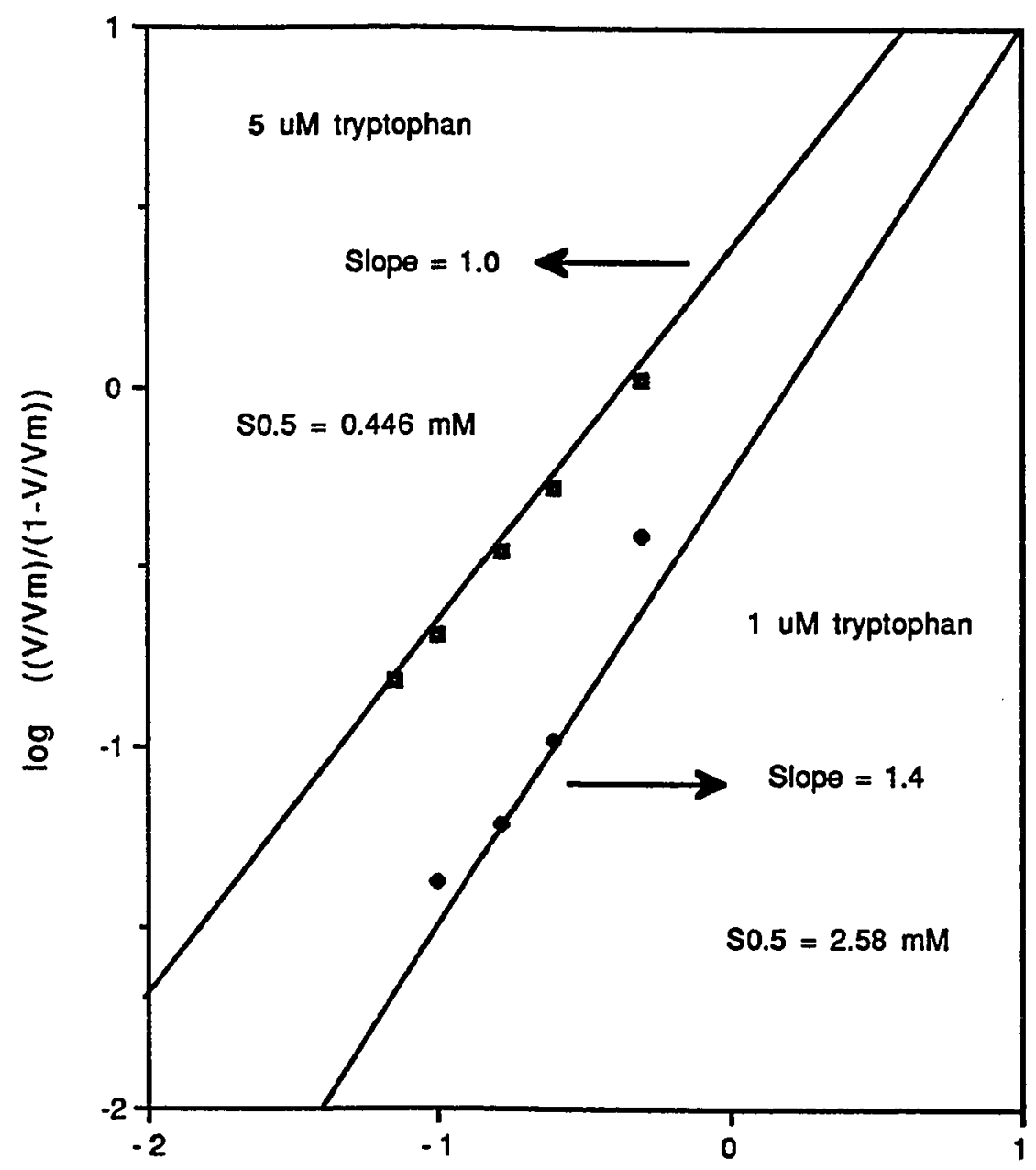

$\log ([$ Chorismate] $(\mathrm{mM}))$

Figure 10. Hill plot of substrate saturation by chorismate at $1 \mathrm{uM}$ and 5 UM tryptophan. 
were done and their average percent activation are also shown in Table 3 .

From these results it is clear that both the removal of $\alpha$-carboxyl and the $\alpha$-amino groups of tryptophan prompted significant loss in enzyme activation, where substitution of the $\alpha$-amino showed the greatest loss of activation of the two. Methylation at the $\alpha$-amino position yielded half the activation potential of tryptophan. Decreased enzyme activity due to the absence of and methylation at the $\alpha$-amino moiety of tryptophan provides strong evidence for this group's participation in $\mathrm{CM}-1$ activation in hydrogen bond formation through its lone pair of electrons. Although it is difficult to surmise the exact nature of the role of the $\alpha$-carboxyl group from these results, it is nevertheless clear that this group is also necessary in promoting maximal activation of $\mathrm{CM}-1$.

Methylation at the first position and the seventh position of the indole ring resulted in little difference in activation when compared to tryptophan. Some loss in activation from methylation at the seventh position of tryptophan may be attributed to steric hindrance from the bulk of the methyl group relative to hydrogen. Almost 
1-Methyl-Tryptophan<smiles>CNC(Cc1cn(C)c2ccccc12)C(=O)O</smiles>

\% TRYPTOPHAN ACTIVITY

92.43

Abrine

45.45

3-Indole-Propionic Acid<smiles>O=C(O)CCc1c[nH]c2ccccc12</smiles>

2.74

Tryptamine<smiles>NCCc1c[nH]c2ccccc12</smiles>

7-methyl-Tryptophan<smiles>Cc1cccc2cc[nH]c12</smiles>
Indole<smiles>c1ccc2[nH]ccc2c1</smiles>

Table 3. To elucidate the structural features of tryptophan involved in the preferential binding and activation of $\mathrm{CM}-1$, selected analogues were substituted in place of tryptophan and incubated with this enzyme. A final concentration of $20 \mathrm{UM}$ of each analogue was allowed to react with $\mathrm{CM}-1$. The degree of activation was based on the percent activity of $\mathrm{CM}-1$ induced by tryptophan at $20 \mathrm{uM}$. 
complete activation with the analogue containing a methylated indole ring at position one indicates hydrogen bonding at this position does not participate in enzyme activation. Indole had very little effect in activating CM-1. This may suggest that this structural feature of tryptophan participates only in recognition for binding to the activator site.

D. Preparation of $\mathrm{CM}-1$ for Amino Acid Analysis

CM-1 for $\mathrm{N}$-terminal sequencing and determination of amino acid composition was isolated on a c-4 reverse phase (RP) column. Because of the short hydrocarbon side chains on this column, large charged proteins were weakly retained on the solid support and could easily be eluted at low acetonitrile concentrations. Under the running conditions outlined in Table $I$, enzyme peaks were easily resolved and collected. To minimize baseline drift during gradient elution, the percent TFA was decreased with a ion comitant increase in percent $A C N$. Because the protein is initially bound to the column, then released as a narrow band by the ACN gradient, dilute solutions of protein are effectively concentrated. In addition, this method exchanges the existing salt buffer to one more organic in composition. This exchange of buffer systems is especially important in 
amino acid analysis since salts are known to interfere with sequencing reactions.

To illustrate the effectiveness of this procedure, an aliquot of purified $C M-1$ and a similar volume of only the enzyme buffer were injected separately onto the column. Both chromatogram are shown in Figure 11. Tris buffer had little or no retention on the RP C-4 column, whereas CM-1 had a retention time of 20.45 minutes. The difference in retention time demonstrates clear separation of the enzyme from its previous buffer. A six second time delay was calculated from the start of the peak to the time it takes it to pass through the detector and out flow line. Collection of the CM-1 peak gave a final volume of 400 ul containing approximately 100 pmol of enzyme based on protein determination at $280 \mathrm{~nm}$ and $235 \mathrm{~nm}$. N-terminal sequences from three separate purifications of $\mathrm{CM}-1$ are shown in Table 4.

One hundred pmol of $\mathrm{CM}-1$ was also prepared for amino acid composition. To determine the appropriate concentrations needed for high resolution of amino acids, two aliquot of the enzyme sample were analyzed, one at 8 pmol and the other at 33 pmol. Results for both analyses are shown in Table 5. Composition ratios for each amino acid were calculated relative to isoleucine. Both samples gave similar ratios. These ratios were typical of most 

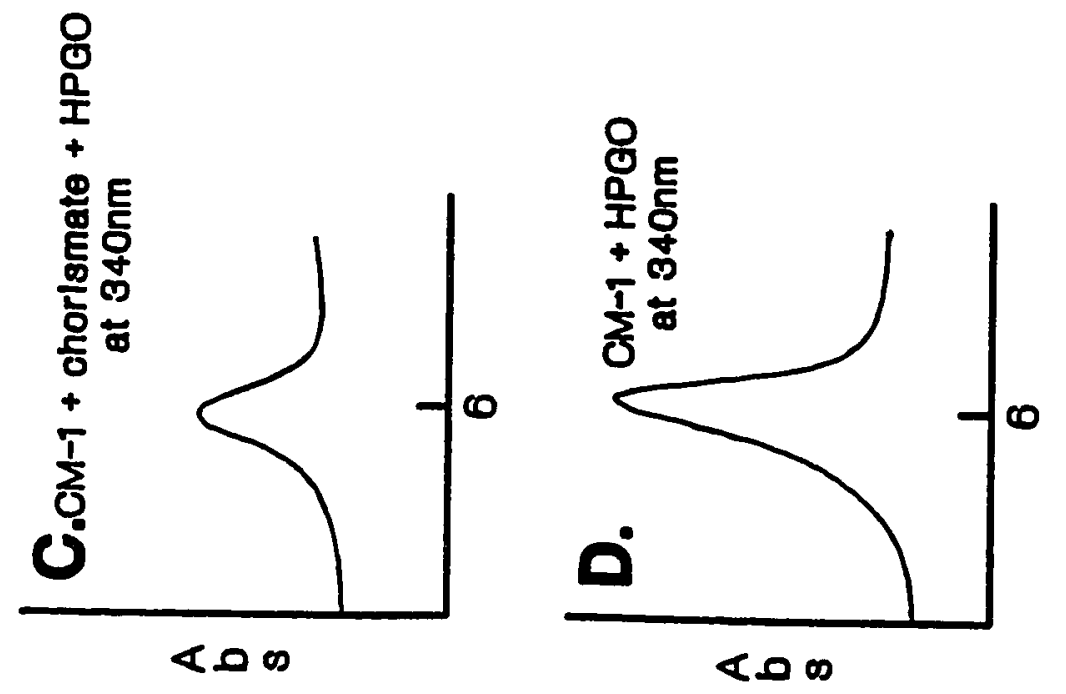

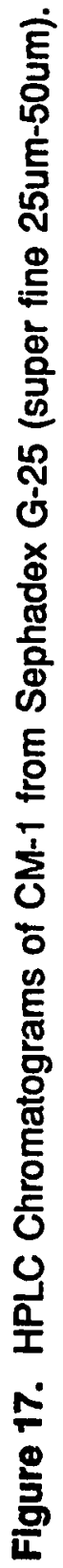
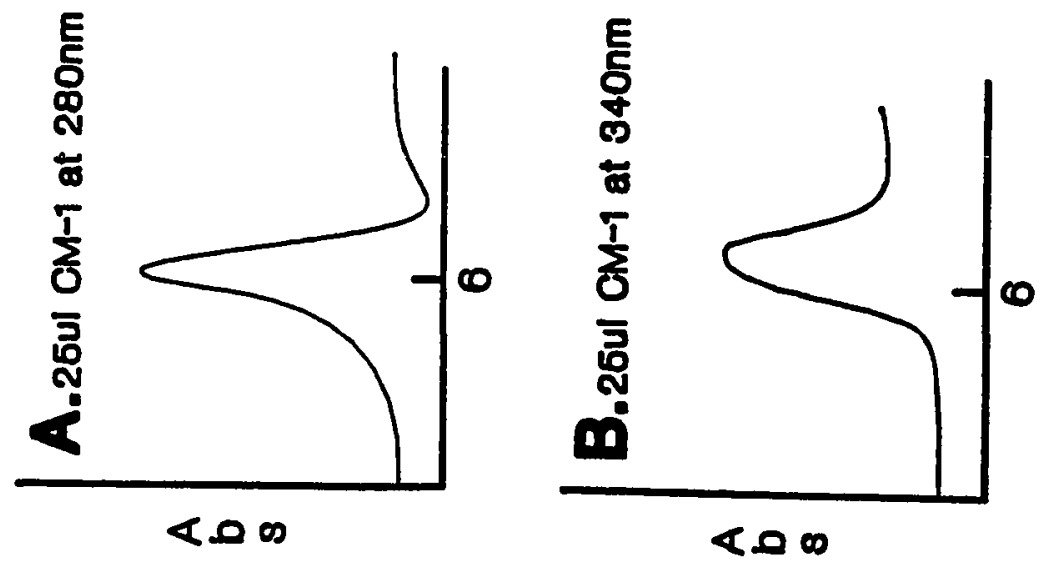


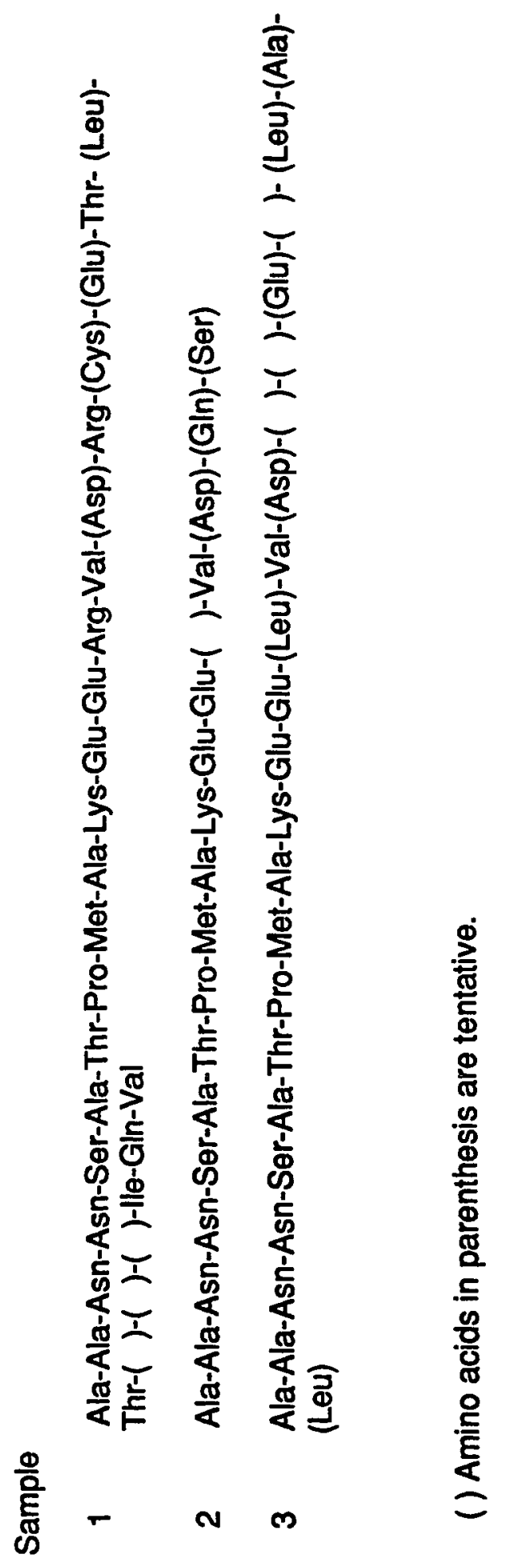


Table 5. Amino Acid Composition For CM-1

Sample 1

Amino Acid Ratio Relative Amino Acid

to Isoleucine Compsition
Sample 2

Ratio Relative Amino Acid to Isoleucine Composition

$\begin{array}{lcccc}\text { Asn } & 0.9 & 23 & 0.9 & 20 \\ \text { Gln } & 1.3 & 34 & 1.5 & 34 \\ \text { Ser } & 0.7 & 18 & 0.9 & 20 \\ \text { His } & 0.2 & 5 & 0.3 & 7 \\ \text { Gly } & 0.6 & 15 & 0.8 & 18 \\ \text { Thr } & 0.5 & 13 & 0.6 & 14 \\ \text { Ala } & 1 & 26 & 1.1 & 25 \\ \text { Arg } & 0.8 & 21 & 0.9 & 20 \\ \text { Tyr } & 0.6 & 15 & 0.6 & 14 \\ \text { Val } & 0.6 & 15 & 0.6 & 14 \\ \text { Met } & 0.4 & 10 & 0.4 & 9 \\ \text { Ile } & 0.5 & 13 & 0.5 & 11 \\ \text { Phe } & 0.4 & 10 & 0.4 & 9 \\ \text { Leu } & 1 & 26 & 1 & 23 \\ \text { Lys } & 0.4 & 10 & 0.5 & 11\end{array}$


large proteins. Tryptophan residues are extremely labile toward acid hydrolysis, therefore were not included in Table 5 .

E. Protein Determination at $280 \mathrm{~nm}$ and $235 \mathrm{~nm}$

Table 6 illustrates the effectiveness and sensitivity of measuring protein concentration based on the difference in absorbance at $280 \mathrm{~nm}$ and $235 \mathrm{~nm}$. Analysis time took less than one minute. Results up to 1.3 ug BSA calculated using Equation 2 showed values close to the actual value of 6.545 $\mathrm{mg} / \mathrm{ml}$ BSA. Limitations at higher dilutions were primarily due to high background absorbance of the pyrophosphate buffer. Therefore, buffer absorbance should be measured to determine the extent of background absorbance.

F. Comparative Analysis of Lysine and Arginine Modification

Two lysine residues are speculated by P.R. Andrews to be the two essential binding groups in chorismate mutase to promote catalysis (Andrews and Haddon, 1979). This is contrary to our present belief that arginine and not lysine is the major amino acid at the active site of $\mathrm{CM}-1$. Andrews' speculations were based on molecular orbital studies of the conversion of chorismate to prephenate. 
Table 6. $\mathrm{mg} / \mathrm{ml}$ BSA Calculated from Absorbance Difference at 235 and $280 \mathrm{~nm}$.

$\begin{array}{ccccc}\text { Dilution } & \text { ug protein } & \begin{array}{c}\text { *counts at } \\ 235 \mathrm{~nm}\end{array} & \begin{array}{c}\text { * counts at } \\ 280 \mathrm{~nm}\end{array} & \begin{array}{c}\mathrm{mg} / \mathrm{ml} \\ \mathrm{BSA}\end{array} \\ & & & & \\ 1: 50 & 130 & 1074696 & 288656 & 6.524 \\ 1: 500 & 13.1 & 261467 & 187088 & 6.174 \\ 1: 5000 & 1.31 & 213945 & 203717 & 8.489 \\ 1: 50000 & 0.13 & 221250 & 212079 & 75.00\end{array}$

* HP 3966A integrator digital readings in response to voltage signal/sec. 
These studies have prompted Andrews to theorize that lysine may participate in bond formation, followed by charge delocalization to both carboxyl groups of transitional chorismate. Although there is no concrete evidence for these assumptions, they are logical and must not be disregarded. Therefore, a comparative analysis between lysine and arginine modifications by maleic anhydride and HPGO respectively were performed. Maleic anhydride, an acylating agent, specifically reacts with the $\varepsilon$-amino group of lysine, resulting in the E-maleyllysine end product (Means and Feeney (1971). The reaction shown on Figure 12 occurs at high $\mathrm{pH}(8-10)$ and at $20^{\circ} \mathrm{C}$. Maleyllysine is stable under these conditions but rapidly reverts back to lysine at low pH's (<pH 3.5). The extent of inactivation by this modifier is easily measured by removing unreacted maleic anhydride by a desalting column and then, assaying for the remaining enzyme activity after designated time points.

p-Hydroxyphenylglyoxal (HPGO), a chromophoric analog of phenylglyoxal is known to specifically modify the guanidino group of arginine residues in proteins by the reaction shown in Figure 13. Much of the work done to characterize the modification of arginine by HPGO is attributed to Feeney's group at UC Davis (Yamaski, et al, 1980). Their studies 


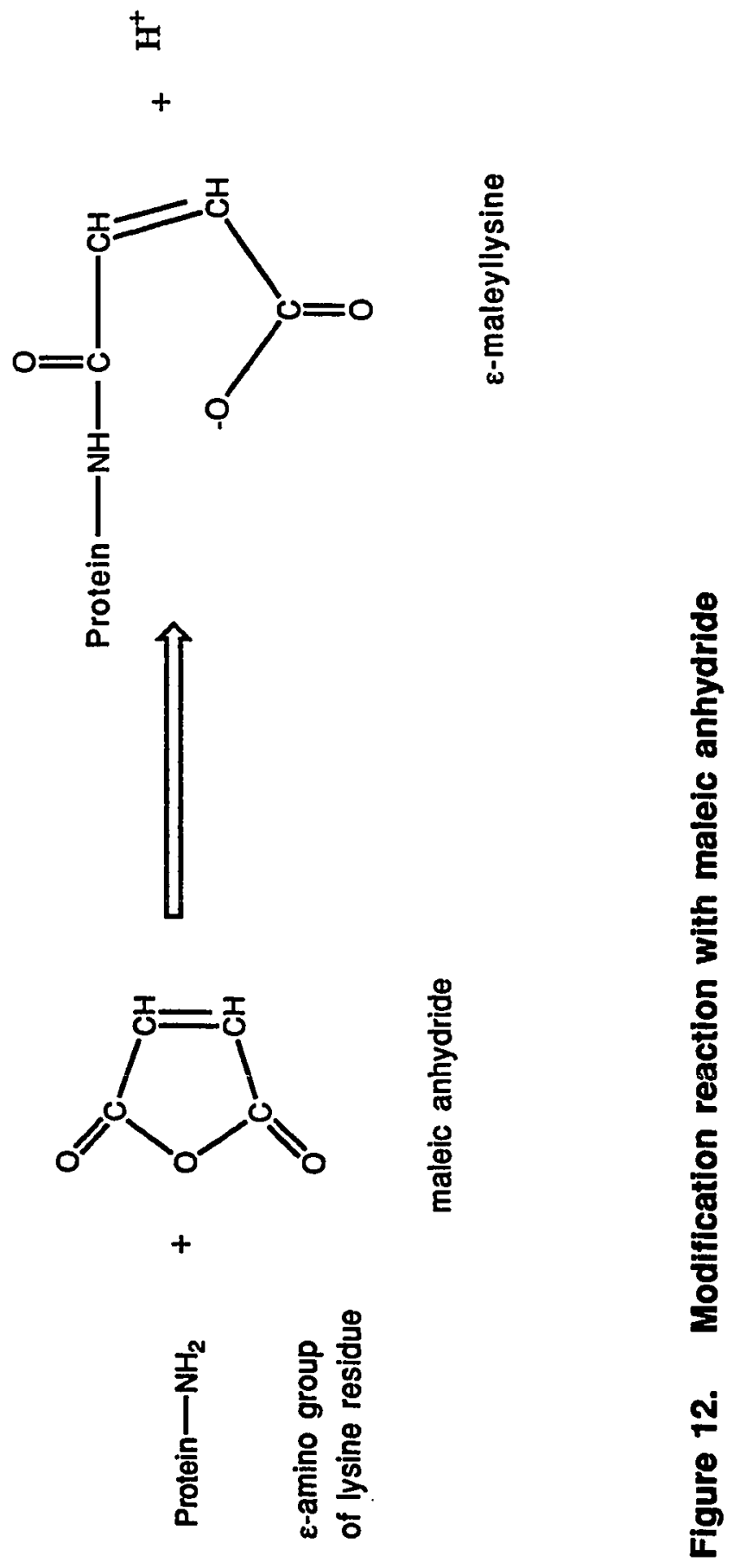


<smiles>N=C(N)NCCCCC(N)C(=O)O</smiles>

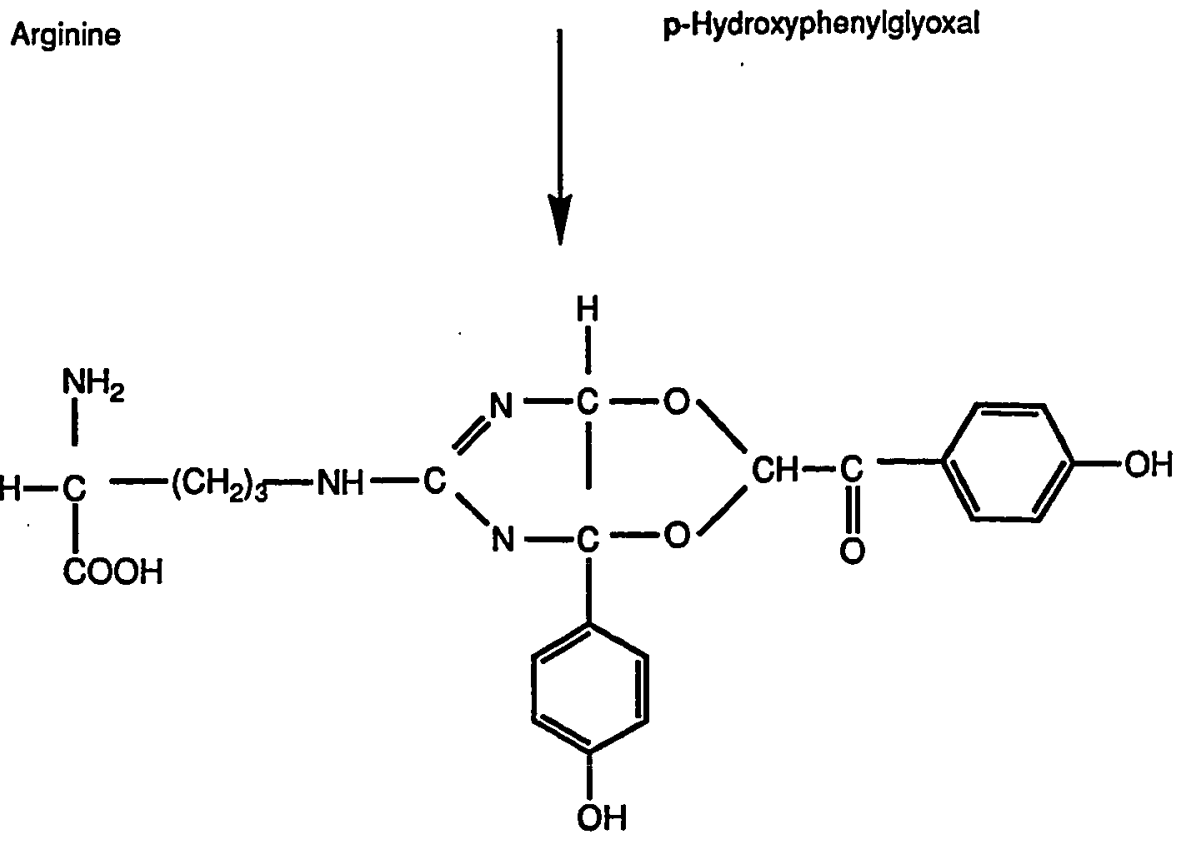
Arg-PGO derivative

Figure 13. Arginine p-Hydroxyphenylglyoxal Reaction 
indicate that HPGO modification takes place under mild conditions between $\mathrm{pH} 7.0-10.0$ at $25^{\circ} \mathrm{C}$. Because of the mildness of these conditions, this particular modification reaction has the advantage of allowing one to assay for biological activity of enzymes stable under these conditions. In addition, formation of the highly conjugated structure of the HPGO-Arginine derivative shown in Figure 13 can be spectroscopically measured at $340 \mathrm{~nm}$ using its molar absorption coefficient at $1.83 \times 10^{4} \mathrm{M}^{-1} \mathrm{~cm}^{-1}$, after removing excess modifier by desalting on Sephadex PD-10 column.

Semipure CM-1 purified from DE-52 chromatography was subjected to modifications by maleic anhydride and HPGO for two time points, one at 30 minutes and the other at 60 minutes. Direct comparison of their percent activity remaining after these time points is shown in Table 7 .

It is evident from these results that HPGO was more effective in inactivating $\mathrm{CM}-1$ than maleic anhydride. After 60 minutes of incubation of each modifier, a loss of more then 98 percent of $\mathrm{CM}-1$ 's activity was observed from HPGO modification, but only 50 percent was observed from maleic anhydride modification. These results suggest that arginine residues are more important in catalysis than lysine residues. 
Table 7. Lysine and Arginine Modification of CM-1

$\begin{array}{ccc}\text { Time (min) } & \begin{array}{c}\text { \% Activity Remaining } \\ \text { in CM-1 } \\ + \text { Maleic Anhydride }\end{array} & \begin{array}{r}\text { \% Acitivity Remaining } \\ \text { in CM-1 + HPGO }\end{array} \\ 0 & 100 & 100 \\ 30 & 56.61 & 26.56 \\ 60 & 50.43 & 0.62\end{array}$


G. CM-1 Inactivation by HPGO

To elaborate on the effectiveness of HPGO in inactivating $\mathrm{CM}-1$, further modification experiments were performed at $6.4 \mathrm{mM}$ HPGO. To determine whether or not protection against inactivation by its substrate was possible, the extent of inactivation by this modifier was observed in the presence and absence of chorismate. In addition, tryptophan's effect on modification by HPGO was also observed. Results are shown in Figure 14. Almost 50 percent of $\mathrm{CM}-1$ 's activity was lost after 30 minutes of incubation with $6.4 \mathrm{mM} \mathrm{HPGO}$. In the presence of chorismate, almost complete protection against inactivation was observed. Modification in the presence of tryptophan increased inactivation by almost 10 percent for both concentrations of HPGO.

Modification of purified $\mathrm{CM}^{-1}$ is shown in Figure 15. Substantial loss in enzyme activity was observed almost immediately after incubation with HPGO. Fifty percent loss in enzyme activity was observed after only 5 minutes of incubation.

These combined results suggest that chorismate's ability to protect against inactivation by HPGO may suggest arginine's possible presence in the active site of $\mathrm{CM}-1$. In addition, the increase in inactivation by HPGO in the 


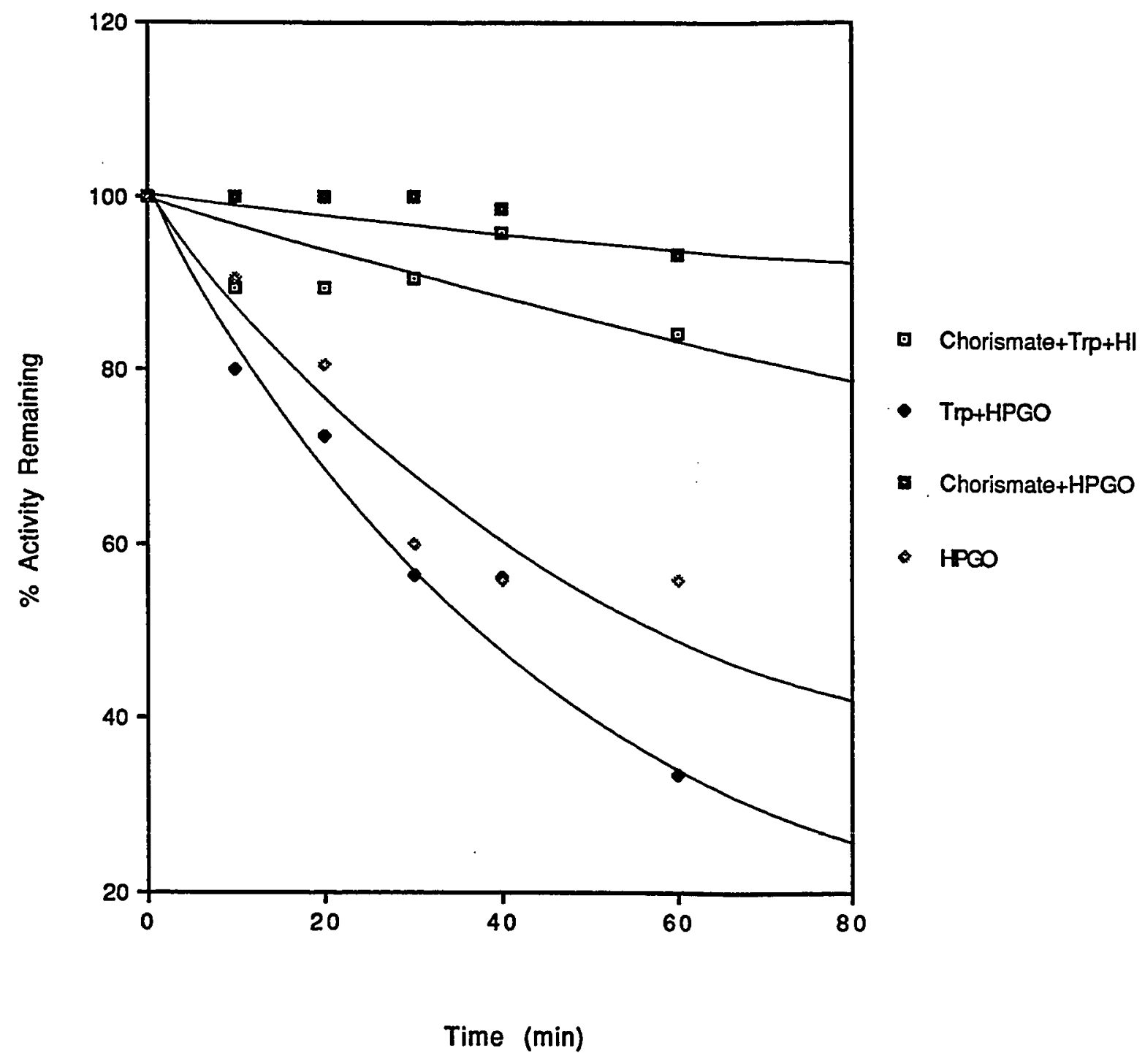

Figure 14. Modification with $6.4 \mathrm{mM}$ HPGO 


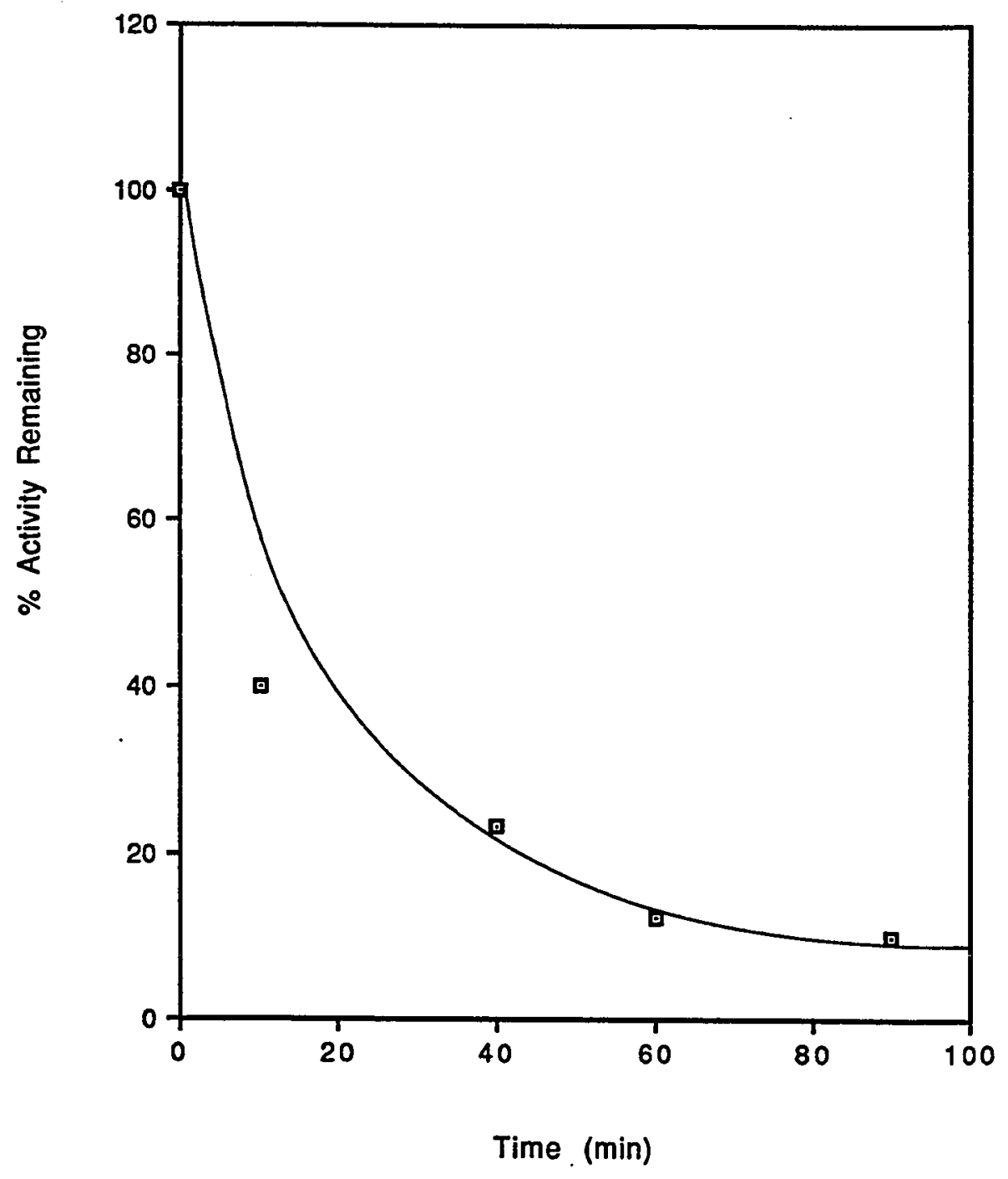

Figure 15. Modification of Homogenous CM-1 with $0.2 \mathrm{mM}$ HPGO 
presence of tryptophan may suggest tryptophan's role in sterically modifying $\mathrm{CM}-1$ conformation to allow greater access to the catalytic site.

\section{H. Quantitation of Arginyl-HPGO Derivative}

Quantitation of modified arginine groups of a protein was made easy by the fact that HPGO will specifically react with arginine residues to form a highly conjugated complex shown on Figure 13. The number of arginyl-HPGO derivative can be spectroscopically measure at $340 \mathrm{~nm}$ using its extinction coefficient at $1.83 \times 10^{4} \mathrm{M}^{-1} \mathrm{~cm}^{-1}$ (Yamashi, et al, 1980). Because HPGO reacts with the guanido groups of arginine, it was necessary to use a buffer system containing no primary amine. Therefore, pyrophosphate was used as the buffer of choice.

The theoretical basis for calculating the number of arginine groups that might be present in the active site of the enzyme is rather simple. If one were to measure the number of modified arginine groups on an enzyme in the presence and absence of its substrate, then the difference between the two values would theoretically give you the number of arginine present in the active site. This theory is based on the assumption that an enzyme's substrate should protect the residues found within the catalytic site from 
modification. A simplistic representation of this approach of quantifying arginine residues in the active site of an enzyme is illustrated in scheme 3.

Perhaps the single limiting factor encountered in quantifying the number of modified arginyl groups in $\mathrm{CM}-1$, was the small amount of protein to work with. A single preparation of $\mathrm{CM}-1$ was often in the pmol range. Therefore, it was necessary to use a detection system sensitive enough to detect such small amounts of the derivatized arginine groups. To circumvent this problem, modified enzyme was injected directly onto Sephadex G-25 column linked to an HPLC integrator set to a maximum absorbance of 0.004 absorbance units. Area counts for each sample were taken and correlated to total arginine-HPGO by using BSA standard curves discussed in the methods section of this thesis. BSA standard curves are shown in Figure 16.

Typical chromatogram for $\mathrm{CM}-1$ samples injected onto the Sephadex G-25 column are illustrated on Figure 17. Area counts for each injection are shown in Table 8 . To obtain the number of modified arginine in the active site of $\mathrm{CM}-1$ using the proposed method discussed above, the protein concentration of $\mathrm{CM}^{-1}$ prior to modification with HPGO was first obtained by measuring its area counts at $280 \mathrm{~nm}$ and extrapolating this value using the BSA protein standard curve shown on Figure 16. An average value of approximately 
1. Incubation with just modifier

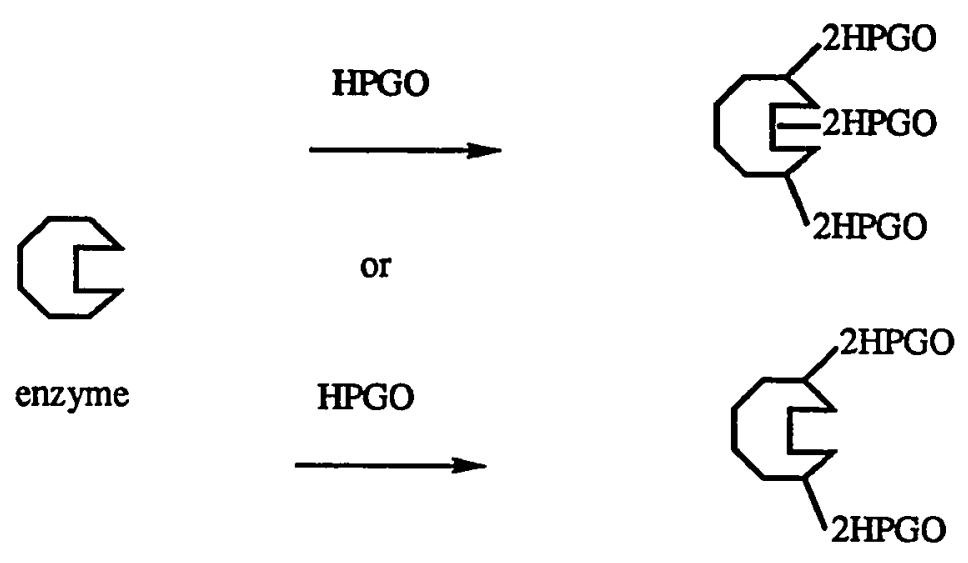

2. Incubation in the presence of modifier and substrate

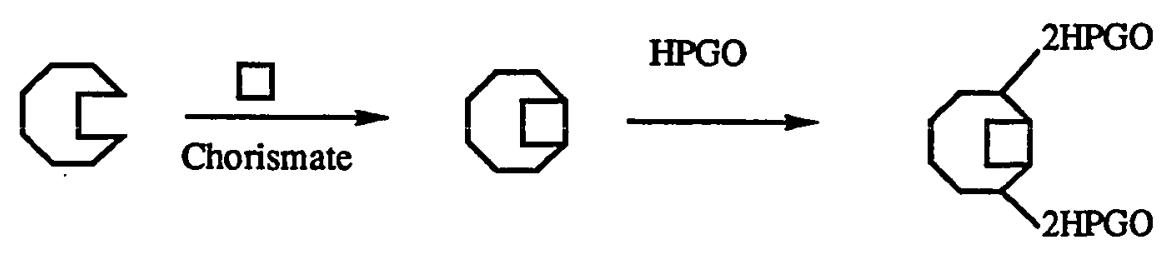

Scheme 3. Arginine Modification Scheme. To estimate the number of arginine present in the active site of the enzyme, the total number of bound HPGO in the absence of substrate is subtracted by the total number of bound HPGO in the presence of substrate. 

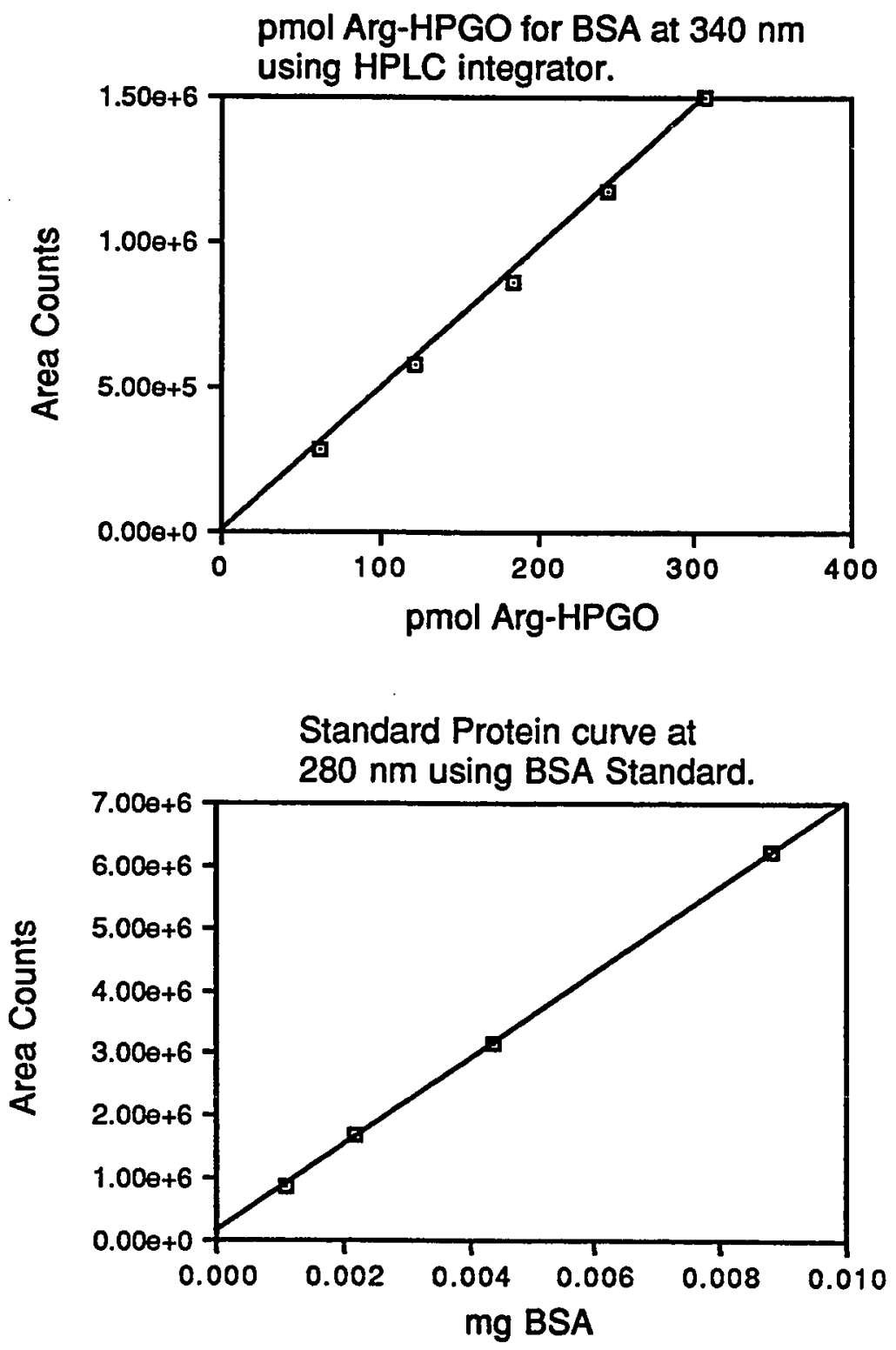

Figure 16. BSA standard Curves for extrapolating protein concentration and quantitating the number of modified arginine groups. 


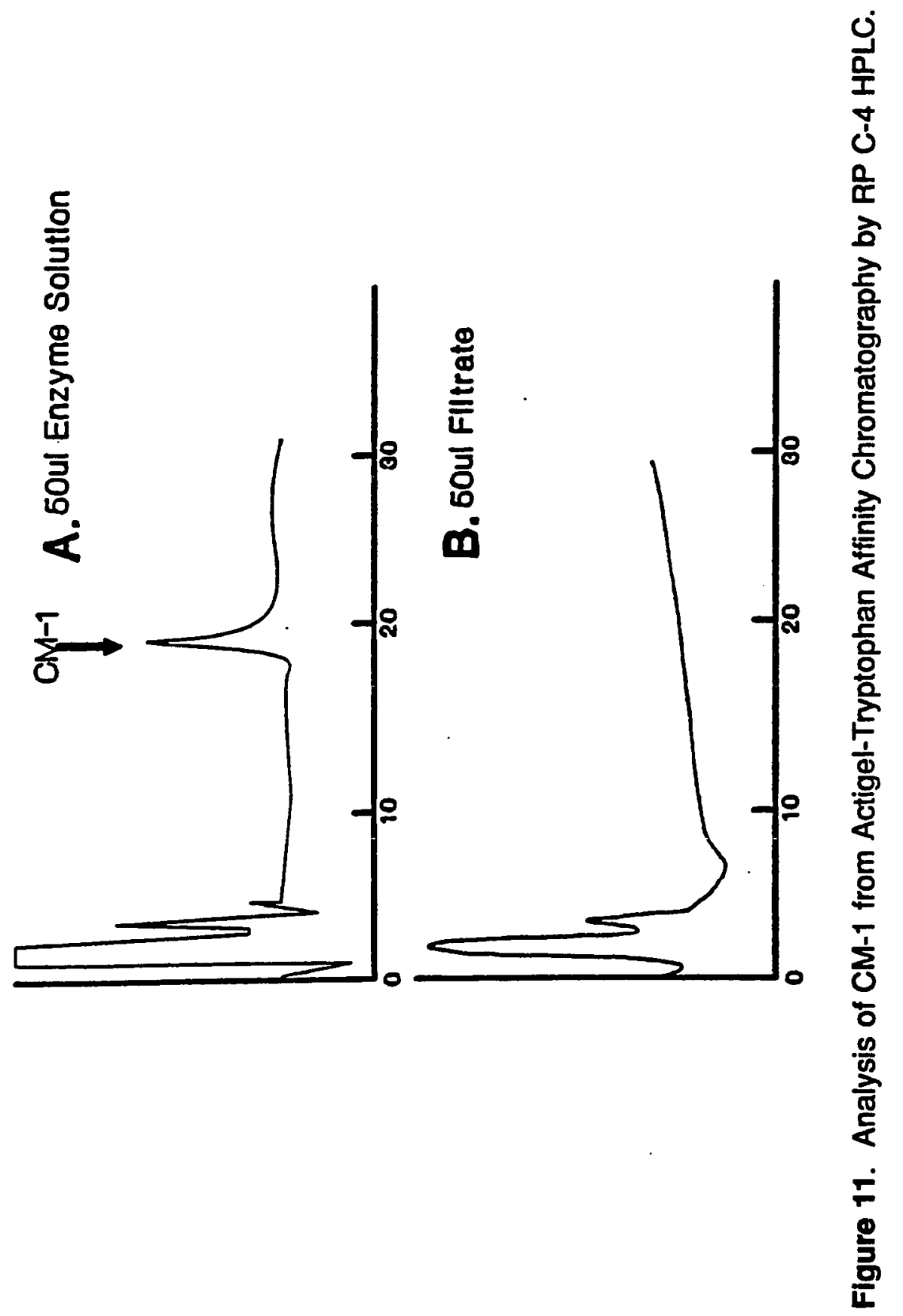



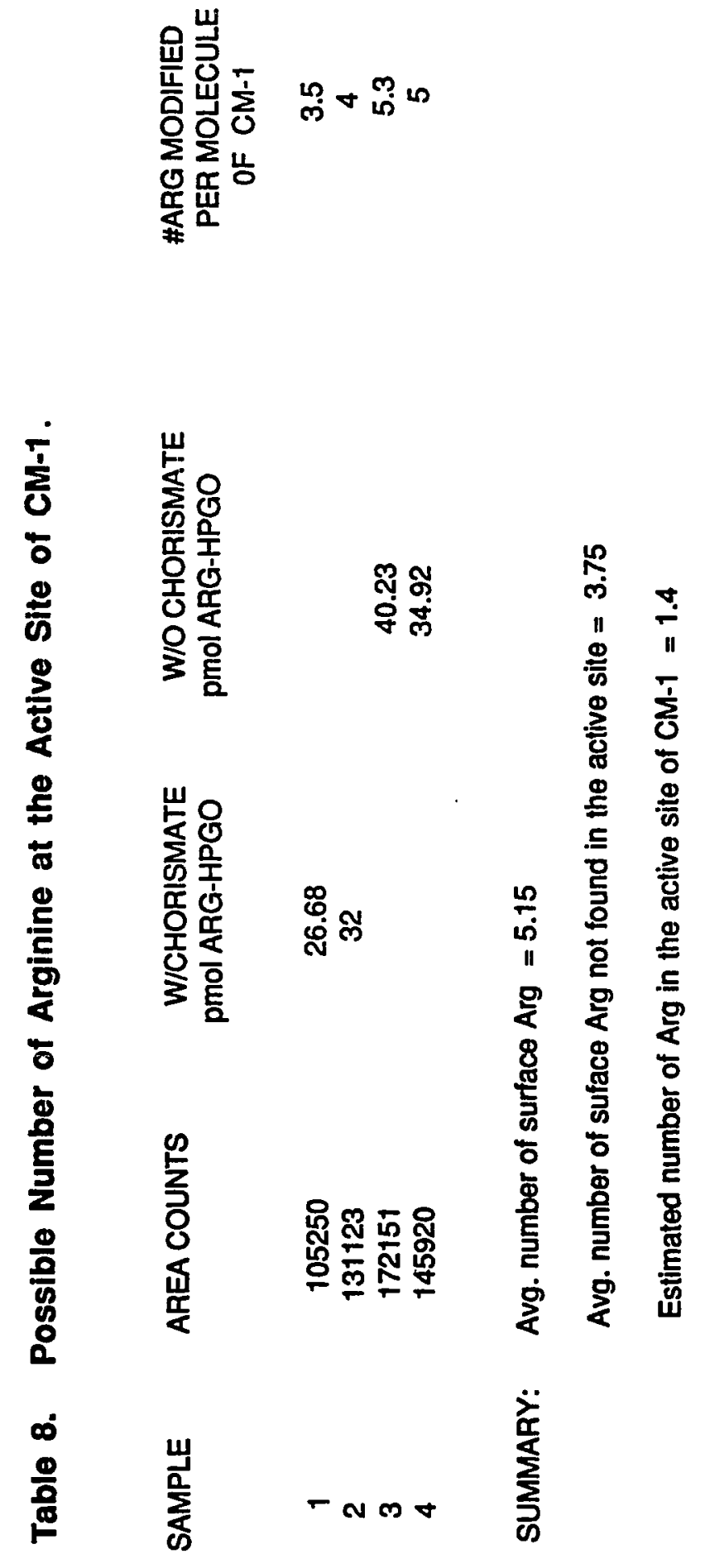
8 pmol of enzyme was measured. Next, area counts for modified $\mathrm{CM}-1$ in the presence and absence of its substrate, chorismate, was measured at $340 \mathrm{~nm}$. Area counts obtained from the control (just $\mathrm{CM}-1$ in buffer read at $340 \mathrm{~nm}$ ) was then subtracted from each of the modified CM-1 data. This corrects for absorbance due to only the enzyme at $340 \mathrm{~nm}$. These corrected values for each of the modified CM-1 reactions were then divided by the protein concentration in order to obtain the number of modified arginine per molecule of CM-1. These values are shown on Table 8. The difference between arginine values obtained from modification in the presence and absence of chorismate is the theoretical value for the number of arginine residues in the active site of the enzyme. An average value of 1.4 arginine residue per active site of $\mathrm{CM}-1$ was calculated. 
v. Discussion

A. CM-1 Purification and Characterization

Chorismate mutase (EC 5.4.99.5) catalyzes the conversion of chorismate to prephenate in the first committed step which separates the synthesis of phenylalanine and tyrosine from the synthesis of tryptophan in the shikimate pathway. CM-1, the chloroplastic isoform of chorismate mutase, is feedback inhibited by its end products, tyrosine and phenylalanine, but strongly activated by tryptophan. CM-1 is essentially inactive in the absence of tryptophan. This requirement for tryptophan facilitates the use of this amino acid as a highly selective affinity ligand for CM-1 purification. $\mathrm{CM}^{-1}$ has been purified to homogeneity, based on SDS-PAGE, 1007-fold using a tryptophan affinity column.

The high affinity of $\mathrm{CM}-1$ for tryptophan was indicated by its half maximal activation $\left(A_{0} .5\right)$ at about $1.5 \mathrm{uM}$ tryptophan and high positive cooperativeness at low levels of tryptophan as illustrated by the Hill plot. Based on substrate kinetic data, tryptophan exerts its activation by lowering the $\mathrm{Km}$ for chorismate rather than increasing Vmax. These results essentially agree with those obtained from partially purified CM-1 isolated from Sorghum bicolor 
(Connelly, 1986). However, in the earlier studies values for $A_{0.5}$ and $\mathrm{Km}$ at saturating levels of tryptophan were 2.1 UM tryptophan and $150 \mathrm{uM}$ chorismate, respectively. High $\mathrm{Km}$ values for crude $\mathrm{CM}-1$ extracts may be due to utilization of substrate by enzymes other than $\mathrm{CM}-1$.

The selective binding of $\mathrm{CM}-1$ to the tryptophan affinity column may be explained by results obtained with tryptophan analogues. As already mentioned, tryptophan is convalently bonded to the affinity matrix via its $\alpha$-amino group. Therefore, the indole ring of tryptophan is the most prominent structural feature exposed to the aqueous phase during $\mathrm{CM}-1$ purification. However, results from the tryptophan analogue studies suggest little involvement of the indole ring in enzyme activation. Only the $\alpha$-amino and the $\alpha$-carboxyl groups of tryptophan were found to be necessary in inducing maximal activation of $\mathrm{CM}-1$. Therefore we suggest that the $\alpha$-carboxyl moiety of tryptophan plays a significant role in $\mathrm{CM}-1$ activation and that the indole ring may participate only in recognition of the activator site of the enzyme.

Homogenous preparation of $\mathrm{CM}-1$ has enabled $\mathrm{N}$-terminal sequence to be obtained. Future work to clone a CDNA encoding $\mathrm{CM}-1$ are presently being investigated in hope of 
eventually expressing it in E. coli to produce large quantities of functional protein. This will permit determination of the entire protein sequence and $x$-ray crystallography to obtain the three dimensional structure of the enzyme.

\section{B. Modification Experiments}

The large amount of research carried out to elucidate the mechanism involved in the isomerization of chorismate to prephenate has made it easy to choose what possible amino acid residue may be involved in the catalysis of $\mathrm{CM}-1$. The established chair-like transition state of chorismate, together with molecular orbital calculations and various chorismate analogues, strongly suggested that only the carboxyl groups of transitional chorismate was sufficient enough to stabilize this conformation (Andrews, et al, 1977; Andrews, et al, 1973; Andrews, et al, 1979; Guilford, et al, 1984; Copley, et al, 1987). Therefore, the choice of amino acid residues in the active site was narrowed down to only those residues that can interact ionically with the negatively charged carboxyl moieties of chorismate. Of the twenty essential amino acid residues, lysine and arginine were chosen as possible amino acid residues that may conceivably interact with the carboxyl groups of chorismate 
in its transition state.

Modification of lysine and arginine with specific reagents were used as a means of determining the presence of these amino acids in the active site of $\mathrm{CM}-1$. The extent of modification was based on biological inactivation of the enzyme. However, the effects of amino acid modification on enzyme activity are not simple to interpret. Change or loss in enzyme activity after modification of groups other than active site residues may be associated with steric blocking by the added substituent or induced conformational change. To distinguish modification of active site residues from those due to steric effects, several criteria should be met. First, enzyme inactivation should be rapid, since catalytic residues are usually the most reactive of amino acids found along the surface of the enzyme. Secondly, inactivation should be blocked by substrate and finally, the number of modified residues required for inactivation should be low. Keeping these criteria in mind, results from the modification experiments are discussed below.

Modification of lysine and arginine by maleic anhydride and HPGO, respectively, were the first initial steps taken to determine the importance of these amino acid residues in catalysis. Selective modification of $\mathrm{CM}-1$ lysine residues with maleic anhydride resulted in a loss of $50 \%$ of the enzyme's activity after 60 minutes of incubation. 
Inactivation induced by modification of arginine residues with HPGO was directly compared with inactivation by maleic anhydride. After 60 minutes of incubation with HPGO, almost complete inactivation of $\mathrm{CM}-1$ 's activity was observed. Loss in CM-1 activity from arginine modification was more than twice as effective in inactivating the enzyme as lysine modification. From a purely speculative point of view, loss of CM-1 activity from maleic anhydride modification may be attributed to random modification of lysine residues along the enzyme, causing conformational changes and subsequently decreasing catalytic activity. Another possibility is that alteration of lysine to form the bulky $\varepsilon$-maleyllysine end product may act to sterically hinder functions of CM-1 thus inhibiting catalysis. In addition, change in charge from positively charged $\varepsilon$-amino to negatively charged malellysine may prevent negatively charged chorismate from binding. These ideas are purely speculative and one should not disregard the possibility of lysine in the active site of $\mathrm{CM}-1$.

One might also argue that the selectivity of HPGO may not necessarily be specific for arginine since the pka values for the guanidino group the $\varepsilon$-amino group is quite similar $(\mathrm{pH} 8-10)$. However, strong evidence of HPGO's selectivity for arginine was shown by Yamasaki's group 
(Yamasaki, et al, 1980). In their experiment rhea ovomucoid, a glyco protein with no arginine but contained an essential lysine, was subjected to HPGO modification under basic pH. Results showed that this glyco protein was unaffected by HPGO. Futhermore, the more pronounced effect on $\mathrm{CM}^{-1}$ 's activity when arginine residues were modified would also suggest that this particular residue is more important than lysine in catalysis. Further modification experiments with HPGO were carried out as a means of clarifying the presence of arginine in the active site of $\mathrm{CM}-1$.

Time course studies with crude extracts of $\mathrm{CM}-1$ from DEAE cellulose in the presence of $6.4 \mathrm{mM}$ HPGO resulted in $50 \%$ loss in enzyme activity after 30 minutes. The slow inactivation of $\mathrm{CM}-1$ in crude enzyme extracts may be attributed to a number of variables such as depletion of the modifier or interference with various components in the enzyme extract. To minimize a majority of these variables, modification was also carried out on purified CM-1. Modification of purified $\mathrm{CM}-1$ resulted in $50 \%$ loss in enzyme activity only after 5 minutes. This result not only eliminated many of the problems associated with modification using crude extract but also indicated rapid inactivation of CM-1 by HPGO. This observation meets the first criterion mention above. Although ideal conditions for modification 
would prefer the use of purified enzyme, the added constituents in the crude enzyme extract may be looked upon as naturally occurring and absence of these components may directly affect the natural conformation of the enzyme. In other words, these components may conceivably be required to set the enzyme as close as possible to its natural environment. Therefore, crude $\mathrm{CM}^{-1}$ extracts were used in all subsequent modification experiments with HPGO. Modification of a particular residue in the active site of an enzyme can be selectively blocked by the presence of its substrate. If enzymatic activity is retained following modification in the presence of substrate but lost in its absence, the presence of this residue in the active site is strongly suggested. In all $\mathrm{CM}-1$ modification experiments with HPGO, incubation with the enzyme's substrate, chorismate, prior to HPGO addition resulted in almost complete protection against inactivation over time. Protection against inactivation by substrate not only suggests arginine's possible presence in the active site of $\mathrm{CM}-1$, but strongly indicates that inactivation was due to arginine modification and not due to steric or conformational effects.

An interesting point to consider is tryptophan's effect on HPGO modification. Inactivation was more pronounced with tryptophan present than if tryptophan were absent. In the 
presence of chorismate and tryptophan, protection against inactivation was not as pronounced as during incubation with just chorismate. This would suggest that tryptophan may play a role in sterically modifying $\mathrm{CM}-1$ conformation to allow greater access to the catalytic site. Perhaps the most difficult aspect to chemical modification is to quantitate the number of modified residue found in the active site (Means and Feeney, 1971). The ability to detect the arginine-HPGO derivative spectroscopically at $340 \mathrm{~nm}$ has made quantifying the number of modified arginine quite simple (Yamasaki, et al, 1980). The only problem associated with this protocol is the limited amount of protein to use. Since quantitation requires homogenous enzyme solution, it was necessary to find a highly sensitive detector to measure very small amounts of modified arginine residues (in the pmol range). An HPLC integrator set at 0.004 absorbance full scale was used to circumvent this problem. Purified $\mathrm{CM}-1$ incubated in the presence of only the modifier gave an average value of 8 arginine residue per molecule of enzyme. This value reflects the number of arginine found along the surface of CM-1. This value is in close agreement with the theoretical value for relative frequency of surface arginine which is approximately 10 residues per molecule of enzyme (Creighton, 1984). Modification of $\mathrm{CM}-1$ in the presence of its 
substrate gave an average value of 6.2 arginine per molecule of enzyme. The difference in the two values obtained in the presence and absence of substrate was approximately 1.8 arginine per molecule of enzyme. These results are in agreement with the initial postulation that there are two arginine in the active site of $\mathrm{CM}-1$. However, even though these results all implicate the presence of arginine in the active site of $\mathrm{CM}-1$, they do not prove the requirement for arginine in catalysis. Site-directed mutagenesis to replace one or both arginine at the active site could provide direct evidence for the catalytic role of arginine. 
1. Andrews, P.R., Cain, E.N., Rizzardo, E., and Smith, G.D. Rearrangement of Chorismate to Prephenate. Use of Chorismate Mutase Inhibitors to Define the Transition State Structure. Biochemistry 16:4848-4852; 1977.

2. Andrews, P.R., Smith, G.D. and Young, I.G. Transition-State Stabilization of Enzymic Catalysis. Kinetic and Molecular Orbital studies of the Rearrangement of Chorismate to Prephenate. Biochemistry 12 : 3492-3498; 1973 .

3. Andrews, P.R. and Haddon, R.C. Molecular Orbital Studies of Enzyme Catalyzed Reactions. Rearrangement of Chorismate to Prephenate. Aust. J. Chem. 32:1921-1929; 1979.

4. Bartlett, P.A., Nakagawq, Y., Johnson, C.R., Reich, S.H.and Luis, A. Chorismate Mutase Inhibitors:Synthesis and Evaluation of Some Potential Transition-State Analogues. J. Org. Chem. 53:3195-3210; 1978.

5. Calvin Ma, K.H. and Davidson B.E. The reactivity of the sulphydryl groups of chorismate/prephenate dehydratase-a bifunctional enzyme of phenylalanine biosynthsis in Escherichia coli K12. Biochim. Biophys. Acta. 827:1-7; 1985.

6. Connelly, J.A. Enzymological Studies of Tyrosine Biosynthesis in Sorghum bicolor. Univ. of California Davis; 1986. Dissertation.

7. Copley, S.D. and Knowles, J.R. The Conformational Equilibrium of Chorismate in solution: Implications for the Mechanism of the Non-Enzymic and the Enzyme-Catalyzed Rearrangement of Chorismate to Prephenate. J. Am. Chem. Soc. 109:5008-5013; 1987 . 
8. Creighton, T.E. Proteins-Structures and Molecular Properties. New York:W.H. Freeman and Company; 1984.

9. Gibson, M.I. and Gibson, F. Preliminary Studies on the Isolation and Metabolism of an Intermediate in Aromatic Biosynthesis: Chorismate Acid. J. Biochem. $90: 248$; 1963 .

10. Gibson, F. Chorismic Acid: Purification and some Chemical and Physical Studies. J. Biochem. 90:256-261; 1964 .

11. Goerisch, H. and Lingens, F. Chorismate mutase from Steptomyces aureofaciens. J. Bacteriol. 114:645-651; 1973.

12. Goers S.K. and Jenson R.A. Separation and characterization of two chorismate-mutase isoenzyme for Nicotinana silvestris. Planta 162:109-116; 1984 .

13. Goers S.K. and Jensen R.A. The differential allosteric regulation of two chorismate-mutase isoenzymes of Nicotiana silvestris. Planta 162 : $117-124 ; 1984$.

14. Guilford, W.J., Copley, S.D. and Knowles, J.R. On the Mechanism of the Chorismate Mutase Reaction. J. Am. Chem. Soc. 109:5013-5019; 1984 .

15. Hilvert, D., Carpenter, S.H., Nared, K.D. and Auditor, M.M. Catalysis of concerted reactions by antibodies: The Clasien rearrangement. Proc. Nat. Acad. Sci. USA 85 : 4953-4955; 1988 .

16. Hudson, G.S., Wong, V. and Davidson, B.E. Chorismate Mutase/Prephenate Dehydrogenase form Escherichia coli K12:Purification, Characterization, and Identification of a Reactive Cysteine. Biochemistry 23:6240-6249; 1984 . 
17. Jackson, D.Y., Jacobs, J.W., Sugasawara, R., Rcich, S.H., Bartlett, P.A. and Schultz P.G. Antibody-catalyzed Claisen Rearrangement. J. Am. Chem. Soc. 110 : $4841-4842 ; 1988$.

18. Jenson, R.A. The shikimate/argoenate pathway: Link between carbohydrate metabolism and secondary metabolism. Physiol. Plant. 66:164-168; 1985 .

19. Lleuellyn, D.J., Daday, A. and Smith, G.D. Evidence for an artifically evolved bifunctional 3-deoxy-D-arabino heplulosonate-7-phophate synthase-chorismate mutase in Bacillus subtilis. $J$. Biol. Chem. 255:2077-2084; 1980 .

20. Loomis W.D. Removal of Phenolic Compounds during the Isolation of Plant Enzymes. Methods in Enzymology, XIII:555-563; 1969 .

21. Means, G.E. and Feeney R.E. (1971) Chemical Modification of Proteins. San Franisco:Holden-Day, Inc.; 1971 .

22. Putnam, A.R. Allelopathic Chemicals-Nature's herbicides in action. Chemical and Engineering News April 4:34-45; 1983.

23. R.M.and Braus, G. A single Point Mutation Results in a Constitutively Activated and Feedback-Resistant Chorismate Mutase of Saccharomyces cerevisiae. J.Bacteriol. 171:1245-1253; 1989 .

24. Singh, B.K., Connelly, J.A., and Conn, E.E. Chorismate Mutase Isoenzymes from Sorghum bicolor:Purification and Properites. Arch. Biochem. Biophys. 243:374-384; 1985. 
25. Singh, B.K. and Conn, E.E. Chorismate Mutase Isoenzymes from Sorghum bicolor: Immunological characterization. Arch. Biochem. Biophys. 246:617-621; 1986.

26. Singh, B.K., Lonergan, S.G. and Conn E.E. Chorismate Mutase Isoenzymes from Selected Plants and Their Immunological Comparison with the Isoenzymes from Sorghum bicolor. Plant Physiol. 81:717-722; 1986.

27. Singh, B.K., Siehl, D.I. and Connelly, J.A. Shikimate Pathway: Why does it mean so much to so many. Oxford survey of plant molecular and cellular biology Vol. 7. in press; [1990]. Available from: Siehl D.L. at Sandoz Crop Protection, Palo Alto, CA.

28. Whitaker, J.R. and Granum, P. An Absolute Method for Protein Determination Based on Difference in Absorbance at 235 and $280 \mathrm{~nm}$. Anal. Biochem. 109:156-159; 1980 .

29. Yamasaki, R.B., Vega, A. and Feeney, R.F. Modification of Available Arginine Residues in Proteins by p-Hydroxyphenylglyoxal. Anal. Biochem. 109:32-40; 1980. 